\title{
Color and context: An ERP study on intrinsic and extrinsic feature binding in episodic memory
}

\author{
ULLRICH K. H. ECKER \\ Saarland University, Saarbrücken, Germany \\ Hubert D. ZimMER \\ Saarland University, Saarbrücken, Germany \\ and Centre for Advanced Study at the Norwegian Academy of Science and Letters, Oslo, Norway \\ AND \\ Christian Groh-Bordin \\ Saarland University, Saarbrücken, Germany
}

\begin{abstract}
Episodic memory for intrinsic item and extrinsic context information is postulated to rely on two distinct types of representation: object and episodic tokens. These provide the basis for familiarity and recollection, respectively. Electrophysiological indices of these processes (ERP old-new effects) were used together with behavioral data to test these assumptions. We manipulated an intrinsic object feature (color; Experiment 1) and a contextual feature (background; Experiments 1 and 2). In an inclusion task (Experiment 1), the study-test manipulation of color affected object recognition performance and modulated ERP old - new effects associated with both familiarity and recollection. In contrast, a contextual manipulation had no effect, although both intrinsic and extrinsic information was available in a direct feature (source memory) test. When made task relevant (exclusion task; Experiment 2), however, context affected the ERP recollection effect, while still leaving the ERP familiarity effect uninfluenced. We conclude that intrinsic features bound in object tokens are involuntarily processed during object recognition, thus influencing familiarity, whereas context features bound in episodic tokens are voluntarily accessed, exclusively influencing recollection. Figures depicting all the electrodes analyzed are available in an online supplement at www.psychonomic.org/archive.
\end{abstract}

Recognition memory can rely on two different processes - namely, familiarity and recollection. Familiarity may be described as a general feeling of prior occurrence, whereas recollection involves the conscious retrieval of specific detail regarding a study episode. The validity of this distinction is mirrored by a wealth of findings from cognitive psychology and neuropsychology and has been extensively discussed elsewhere (see Ecker, Groh-Bordin, \& Zimmer, 2004; ${ }^{1}$ Mecklinger, 2000; Yonelinas, 2002; Zimmer, Mecklinger, \& Lindenberger, 2006a).

Especially important for the present article, the processes of familiarity and recollection are associated with distinct event-related potential (ERP) old-new effects (Curran \& Cleary, 2003; Friedman \& Johnson, 2000; Mecklinger, 2000; M. E. Smith, 1993). First, around $400 \mathrm{msec}$ poststimulus-onset, old items elicit more positive-going waveforms mostly over midfrontal electrodes in an N400-like component (the FN400 effect). This effect is usually associated with familiarity, due to its insensitivity to depthof-processing manipulations (Rugg et al., 1998) and its presence in amnesics with focal hippocampal damage and above-chance recognition performance (Düzel, VarghaKhadem, Heinze, \& Mishkin, 2001). Second, in a time window of about 500-700 msec, old items elicit more positive potentials over left-parietal electrodes, reflecting recollection processes (the LPC effect). The association of the LPC effect with recollection is due, inter alia, to the fact that it is larger for remember than for know responses (Düzel, Yonelinas, Mangun, Heinze, \& Tulving, 1997; M. E. Smith, 1993) and to its sensitivity to depthof-processing manipulations (Paller \& Kutas, 1992; Rugg et al., 1998). Furthermore, Curran (2000; Curran \& Cleary, 2003) has repeatedly demonstrated that for almost equally familiar but slightly modified lures, the FN400 effect is unaffected, whereas the LPC effect is largely reduced or absent (see below and the General Discussion section).

Turning to the psychological basis of recollection and familiarity, we assume that there are different types of memory traces that familiarity and recollection operate upon, and we have labeled these representations object tokens and episodic tokens, respectively (cf. Ecker et al., 2004). An object token represents intrinsic information

U. K. H. Ecker, u.ecker@mx.uni-saarland.de 
(within-item features of the object - e.g., color) and can be thought of as a consolidated object file (Treisman, 1992, 2006), binding features supplied by fairly automatic datadriven processes when an object is attended to. It contains no information about the context the object was originally encountered in and, thus, allows for episodic recognition without retrieval of any contextual detail. At retrieval, all available information is (again, involuntarily) reactivated; that is, the object token will typically be activated in whole. The familiarity signal then results from the match between the object token in memory and the object file in perception (when the test stimulus is attended to).

On the other hand, the episodic token integrates object information with multimodal contextual (extrinsic) information and, thus, supplies the basis for recollection. Note that intrinsic information may be integrated into the episodic token as well - in particular, if elaboration takes place at study (e.g., if subjects generate predicates such as "that's a funny color"); there can thus be some redundancy in feature representation (cf. perceptual vs. reflective processes; Johnson \& Chalfonte, 1994). Furthermore, recollection is considered a rather controlled process, so feature retrieval is deliberate and piecemeal (cf. Wilding, Fraser, \& Herron, 2005). This also implies that the retrieval of irrelevant context information can be inhibited. Only recollection via the episodic token should strongly rely on the hippocampus, whereas adjacent cortical regions should be able to support familiarity via the object token. Thus, the model encompasses a neurocognitively plausible hierarchy (see Aggleton \& Brown, 1999).

Evidence concerning the distinction of two different kinds of tokens comes from various sources, including the animal, neuropsychological, and imaging literature (for a review, see Ecker et al., 2004; Zimmer, Mecklinger, \& Lindenberger, 2006b). The distinction between intrinsic and extrinsic features is not new, however; it was put forth already by Solomon Asch and John Ceraso as early as 1960 (Asch, Ceraso, \& Heimer, 1960; Ceraso, 1985, 1990; see also Garner, 1974).

Strong support for the linking of intrinsic information to familiarity and extrinsic information to recollection comes from the neuropsychological literature. For instance, a relative sparing of item memory, as compared with associative memory, has been reported for patients with adult or perinatal onset hippocampal lesions (Baddeley, Vargha-Khadem, \& Mishkin, 2001; Holdstock, 2005). A similar dissociation has been reported for the elderlyfor example, by Cabeza (2006), who has linked familiarity and recollection to item versus relational memory, respectively, although he stresses that both involve associative processing, but to a different degree (see also Mandler, 1980). Accordingly, Yonelinas (2002) stated that "familiarity is not expected to support associative memory for two distinct items, unless the two items can be unitized or treated as a single larger item" (p. 447). We thus argue that familiarity memory is associative only as long as the to-be-associated information is part of the specific object (i.e., intrinsic) and its unitized representation (the object token). Similarly, Spencer and Raz (1995) have reported that age-related memory deficits affect spatiotemporal context memory more than memory for perceptual context (more likely to be encoded in conjunction with content) and content itself (see also Naveh-Benjamin, 2000, 2006). Likewise, Park and colleagues (Park, Puglisi, \& Lutz, 1982; Park, Puglisi, \& Sovacool, 1983) found stronger age effects on position than on pure item memory.

Concerning processing control, Troyer and Craik (2000) have argued that intrinsic information is automatically processed, whereas extrinsic information requires more attentional resources and intentional processing. They showed that divided attention at encoding and retrieval leads to worse recognition only of extrinsic information, which suggests that intrinsic binding takes place rather automatically. Accordingly, we argue that intrinsic features are involuntarily activated when an item is retrieved. Evidence for this can be found in sensory mismatch effects observed in episodic object recognition (Cooper, Biederman, \& Hummel, 1992; Jolicœur, 1987; Zimmer, 1995; Zimmer \& Steiner, 2003; for a review, see Engelkamp, Zimmer, $\&$ de Vega, 2001): When the size, orientation, or color of objects is changed from study to test, reaction times (RTs) increase, even if the feature is irrelevant for the old-new decision (inclusion task). This is not to say, however, that these effects are always and only based on familiarity. For instance, Yonelinas and Jacoby (1995) found size congruency effects on both familiarity and recollection measures. Thus, we do not argue against an influence of perceptual manipulations on recollection; after all, the episodic token in our model may comprise both item and contextual information. Further empirical support for the involuntary activation of intrinsic information can be found in studies on color memory. Wilton (1989) found better color recognition for surface versus background color even following incidental study. Similarly, Walker and Cuthbert (1998) found incidental memory effects of color only if color and shape were unitized - that is, color was part of the perceptual unit of the item (see also Guillem, Bicu, \& Debruille, 2001; Zimmer \& Steiner, 2007). Obviously, information regarding the sensory features of an item is part of its memory representation, and this information is involuntarily accessed in episodic object recognition, even if the features are irrelevant for recognition.

Regarding manipulations of extrinsic context, the picture is less clear. Studies of context effects on item memory delimit a quite heterogeneous field with rather diverse definitions of what is considered context. For instance, in a review by S. M. Smith and Vela (2001), it was reported that context effects in recognition memory decrease if context processing is suppressed either at study or at test. However, only studies in which incidentally encoded, global context was manipulated were included in this study. The term global context refers to slow-changing contexts, such as the room an experiment takes place in. It seems to be widely accepted that the hippocampus proper is important for the integration of global context. In order to have a more straightforward test of our hypotheses, in the present experiments, we used more object-like, local contexts that were clearly contextual by definition but not too abstract, to make sure that the contexts were perceptually similar to the objects and not located in the attentional 
periphery. There are only a few studies in which the effects of local context manipulations have been investigated. Murnane, Phelps, and Malmberg (1999), for instance, reported context effects on word recognition, but only in a rich context condition (e.g., words written on a blackboard in a classroom scene; as opposed to simple contexts, such as location or background color). They argued that the probability of the integration of contextual information is a function of its meaningfulness. The more meaningful a context is, the easier its integration by way of elaboration. The subjects in the experiment of Gooding, Mayes, and Meudell (1997) studied complex arbitrary patterns in the context of unique objects. The authors found strong context effects even in the accuracy data. In summary, these results suggest that context influence increases with a decrease of item distinctiveness and with an increase in the richness of context information.

We should stress here that it is not easy to exactly define which features are intrinsic and which are extrinsic. Even after decades of research, it is still not entirely clear what indeed defines an object. Following Reinitz (2003; Reinitz \& Hannigan, 2001, 2004), all features that are simultaneously attended to might become a unit in perception and memory. Both behavioral and imaging studies suggest that whole objects are preferably selected by attentional processes in perception and that, therefore, objects are likely units of memory (Duncan, 1984; Duncan, Martens, \& Ward, 1997; Duncan \& Nimmo-Smith, 1996; O'Craven, Downing, \& Kanwisher, 1999). In our terms, focal attention on an object results in the generation of an object token driven by bottom-up processes interacting with topdown processes, and this object token binds intrinsic information as grouped by perceptual mechanisms.

Proceeding from the behavioral to the ERP literature, the ERP method has, in recent years, been employed in order to assess the plausibility of dual- versus singleprocess accounts of recognition memory. More specifically, source memory paradigms were used in many cases to draw inferences about familiarity and recollection from ERPs. Fortunately for our present concerns, these studies have often involved perceptual manipulations, so given the presumption that ERP effects can be taken as correlates of familiarity and recollection, these manipulations can be reviewed under the present perspective. In these studies, recollection is inferred from the retrieval of a specific piece of source information. This could, in fact, be any aspect of the studied item or its context - for instance, its color (e.g., Cycowicz, Friedman, \& Snodgrass, 2001) or its location (e.g., Van Petten, Senkfor, \& Newberg, 2000). If a subject recognizes an item as old but fails to correctly assess the specific feature, the response is thought to reflect familiarity without recollection.

In some cases, the items are studied together with a specific feature (e.g., items are presented in different colors or at different screen positions) and are then tested neutrally (e.g., in black or at the center of the screen). In these studies, there seems to be a tendency for larger ERP old-new effects when source information is additionally retrieved. For instance, Cycowicz et al. (2001) presented colored line drawings at study that were then tested in black and found that the parietal old-new effect associated with correct source retrieval had a different, more frontally distributed topography, as compared with incorrect source judgments. One disadvantage of this procedure is that all old test items will be equally familiar, because the feature of interest is always different from that at study.

To examine familiarity processes more thoroughly, a better suited approach is to change the respective feature only for a subset of old items and then compare same and different repetitions (i.e., old items presented in the same or a different color/position). A difference in a dependent variable between same and different conditions (i.e., a congruency effect) is then interpreted as an index of source memory. Taken together, there is a tendency for larger ERP old-new effects when no item features are changed from study to test. However, the evidence is still quite mixed. Wilding, Doyle, and Rugg (1995) reported a behavioral congruency effect (slower and less accurate responses) in a source memory task in which word modality was manipulated; however, they found no ERP congruency effects. With a procedure quite similar to the one adopted here (manipulating the color of line drawings), Friedman, Cycowicz, and Bersick (2005) found congruency effects in their behavioral exclusion test data (but not in a pure old-new recognition test). There were no reliable ERP congruency effects, although the authors reported a tendency toward a larger parietal old-new effect (and visual inspection suggests also a larger mid-frontal effect) for old-same presentations. Using a somewhat more perceptual study task, Ranganath and Paller (1999) manipulated the aspect ratio of images and found congruency effects in both the behavioral and the ERP data (which was reported across both an item and a source memory task), although the reported ERP old-new effect had a rather broad and posterior distribution. They concluded that old-same items were more perceptually vivid than old-different ones. Van Petten et al. (2000), again comparing an old-new with a source memory test, reported no significant congruency effects when manipulating object position. Senkfor and Van Petten (1998) found congruency effects in a source memory task when the voice of spoken words was manipulated, but no congruency effects in an item memory task. They interpreted significantly longer RTs in source versus item memory tasks and late frontal old-new effects as an indication of two successive processes of item retrieval and source integration. Finally, Schloerscheidt and Rugg (2004) manipulated the pictureword format of stimuli and reported congruency effects in RT and ERP data (in both the FN400 and the LPC components; larger for pictures than for words at test) in an inclusion task. Thus, given the wealth of behavioral studies reporting such effects, it is somewhat astonishing that there are hitherto relatively few ERP studies (see also the references below to Groh-Bordin's work) unequivocally demonstrating RT congruency effects in an item memory task (thus suggesting that these effects are not due only to task demands).

Taken together, perceptual study-test manipulations frequently affect behavioral indices of recognition memory, but the neural correlates of this influence remain 
somewhat unclear. For our purposes, there is one important shortcoming of the reviewed studies with regard to the features they utilize: Inferences about recollection and familiarity are made on the basis of whether or not a specific feature is retrieved or whether or not an altered feature influences recognition. Thereby, intrinsic features of the items (e.g., color) and extrinsic features of the study context (e.g., study list) are treated as equivalent, without considering the possibility that these features contribute differently to the processes of familiarity and recollection. Our intrinsic/extrinsic distinction could thus have important consequences and could at least partially resolve ambiguities in previous source memory research. For instance, if we assume that familiarity is influenced only by intrinsic information, it becomes clear why some studies in which rather extrinsic features have been used have not reported any effects on the ERP component associated with familiarity (e.g., Van Petten et al., 2000). With regard to the two-successive-processes account of Van Petten and Senkfor mentioned above, we agree that there are two distinctive processes but argue that they are only really successive if the to-be-integrated feature is extrinsic (e.g., spatial position) or if the processing of the feature per se takes considerably longer than the identification of the item, as is the case with the voice of spoken words (Senkfor \& Van Petten, 1998).

ERP recognition memory studies more explicitly testing the influence of perceptual features include a study by Curran and Cleary (2003), who reported an ERP congruency effect selectively on the LPC when the orientation of pictures were manipulated in an exclusion task (following intentional study). In contrast, Groh-Bordin, Zimmer, and Mecklinger (2005), who also manipulated the orientation of picture stimuli, found RT congruency effects accompanied by a selective ERP congruency effect on the FN400 in a pure old-new task with no feature relevance (following incidental study). Employing a procedure similar to the one here, Groh-Bordin, Zimmer, and Ecker (2006) reported RT congruency effects when the color of objects was manipulated in an inclusion task with subsequent feature decision. Their behavioral findings were accompanied by attenuations of both early and late ERP old-new effects for incongruent items.

One of the few ERP studies in which local context effects on object recognition were investigated was conducted by Tsivilis, Otten, and Rugg (2001). They had subjects study objects embedded in different complex landscape scenes. Contrary to our position, they found context effects on RTs in an object old-new decision but no electrophysiological correlate of this behavioral effect, so their results remain somewhat inconclusive (see the General Discussion section). In conclusion, it is clear that perceptual manipulations do affect the electrophysiological correlates of recognition memory, although the exact constraints remain somewhat unclear.

Given our model, intrinsic and extrinsic information should be differently represented and/or processed in memory, and thus the study-test manipulation of intrinsic and extrinsic item features should affect the processes of familiarity and recollection differently. This prediction was tested by analyzing both behavioral and electrophysiological (ERP) data in two object recognition experiments. In none of the reviewed studies, using behavioral and/or ERP methods, were changes of intrinsic and extrinsic information simultaneously contrasted, holding all other aspects of the study episode constant. This was the aim of Experiment 1.

\section{EXPERIMENT 1}

\section{Design and Hypotheses}

Subjects studied colored objects (silhouettes) presented on arbitrarily shaped context figures in an intentional study condition. At test, all the subjects were first required to judge the old-new status of the objects, ignoring their color and context (object old-new decision). From study to test, we manipulated either the color of the object (intrinsic feature) or the shape of the background (extrinsic feature). This was a between-subjects manipulation, so there was a color and a context group (i.e., in each group, only one feature was in fact manipulated). For half the repeated items, either the color or the background shape was altered from study to test; the other half of the items were repeated identically. Following each old response, items were presented again, and the subjects were asked to assess whether or not the respective feature had changed (feature decision).

Concerning the present choice of intrinsic/extrinsic features, we chose local, object-like contexts, because global contexts, such as the experimental room, are very different from actual objects and we wanted to make sure that the effects we measured were not due to these basic differences. This implies that our operationalization of context is perhaps not the most typical but a quite conservative one with respect to our hypotheses; the image of a tent presented in front of a star-shaped background could be perceived (and memorized) as such or simply as a star with a tent on it (i.e., one unitized object). Turning to the intrinsic level, color should be processed as an intrinsic feature, given previous research (see above and also Zimmer \& Steiner, 2007). ${ }^{2}$ We assume that the present choice of features will fit most researchers' definitions, since it incorporates both a spatial and a figure/ground contrast.

Changing an intrinsic feature of the object should involuntarily hamper recognition performance (i.e., RTs should increase). In contrast, subjects should be able to mask out the irrelevant extrinsic context information, and hence, a changed background should not impair object recognition. Importantly, however, we expected both features to be voluntarily recognizable to a comparable degree, demonstrating that the specific associations of objects with colors and contexts, respectively, had been learned and were potentially accessible at test (as indexed by feature decision performance). This would constitute hitherto lacking behavioral evidence, taken from a single experiment, supporting the claim of differential processing of intrinsic versus extrinsic features.

As far as object decision ERPs are concerned, we hypothesized that the manipulation of the intrinsic feature should generally affect old-new effects. The rationale 
behind this claim is that the processes underlying these effects should be sensitive to an exact match of cue and memory representation, thus signaling reoccurrence (Giovanello, Schnyer, \& Verfaellie, 2004). In particular, the manipulation of color should become apparent in a modulation of the frontal old-new effect. However, because of the explicit and associative learning instruction, color information is potentially also bound into the episodic token by more controlled processes. Hence, the manipulation of color might also modulate parietal effects. In contrast, the manipulation of context should not affect the FN400 effect. Note that this is the central point here, since our model allows for effects of intrinsic features on the LPC but precludes effects of extrinsic features on the FN400. Finally, the assumption that extrinsic information as part of the episodic token influences recollection suggests that the LPC should be affected by the contextual manipulation; yet the subjects were instructed to ignore feature manipulations, so to the extent that they followed instructions, the extrinsic manipulation should not affect the LPC.

\section{Method}

\section{Materials and Procedure}

In Experiment 1, an object feature (color) or the shape of an arbitrary gray background (context) was manipulated between study and test. In the study phase, the subjects were presented 80 images of everyday objects, which could appear in one of four different arbitrary colors (red, blue, green, or yellow) and on one of four distinct backgrounds (see Figure 1; presentation time was $3.5 \mathrm{sec}$, the interstimulus interval was $2.5 \mathrm{sec}$ ). In fact, every specific object existed only in two color versions (Figure 1 thus displays two different objects), and some attention was paid to the assignment of colors, although these were largely arbitrary. Yet, since most objects have some more or less typical colors, we made sure that the colors were always equally appropriate across these two versions (e.g., a green and a blue t-shirt), although no formal analysis was carried out. In particular, there were no color changes that would have implied a change of meaning (e.g., red apple $\rightarrow$ green apple $=$ "Fuji" $\rightarrow$ "Granny Smith"). The item set largely consisted of artifacts $(77 \%)$. There were two study-test blocks, and every item was presented twice within each study block to enhance encoding. Altogether, the subjects were presented 2 (repeated presentation of same items in one study block) $\times 40$ (number of individual items per study block) $\times 2$ (dual study-test blocks) study items.

The study instructions were to intentionally memorize the specific combination of object, color, and background. At test, the 80 old items were intermixed with 80 new items, and more important, 40 old items were presented either in a different color or on a different background (i.e., in a new context). This color-context factor was varied between subjects; that is, in one particular group of subjects, only one feature (color or context) was manipulated. However, the subjects were led to believe that the computer randomly selected and assigned one of the two conditions before each test block. Thus, if the subjects in the color group had judged whether the objects' colors had changed in the first test block, they still thought that both conditions were equally probable in the second test block. Thereby, we made sure that the subjects did not focus on the feature that they had assessed in the first test block during the second study block. Nevertheless, we included a block factor in behavioral analyses in order to control for possible block effects. First- and second-presentation colors and contexts, as well as their transitions, were counterbalanced within each subject; that is, seeing a green object was as likely as seeing a yellow one, and the transition from red to blue in a different study-test case was as likely as a transition from red to green or any other combination. The same held true for contexts.

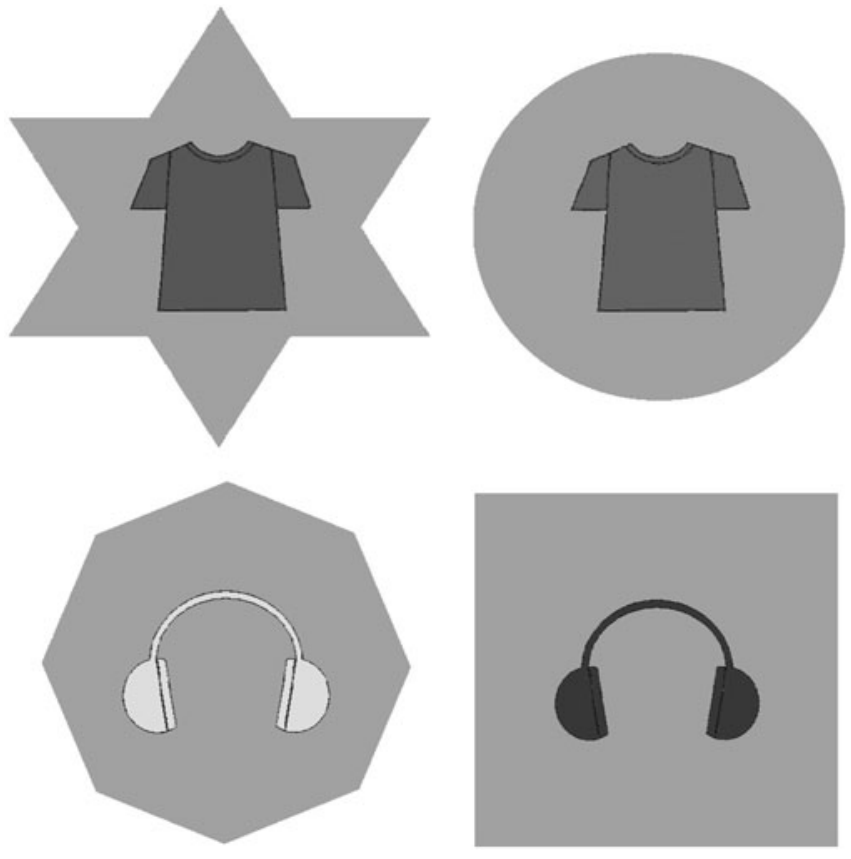

Figure 1. Examples of the items used. The objects appeared in red, blue, green, or yellow; the backgrounds were gray. Only color or context was changed at test in different cases; both features were never altered at the same time.

At test, the subjects had to make two succeeding decisions concerning every item. First, they had to decide whether or not the object had been presented before, independently of color or background (old-new decision). This inclusion task was the focus of interest. We emphasized the need for quick responses in the subjects' instructions concerning the old-new decision. The test trial structure was as follows. A fixation cross was presented centrally for $300 \mathrm{msec}$, followed by a blank screen for $200 \mathrm{msec}$. The item was presented for $2 \mathrm{sec}$, and the subjects were to respond old or new by pressing a key, with a maximum RT of $3 \mathrm{sec}$ from stimulus onset. In the case of an old response, the item was presented again (after a 1,500-msec blank screen), together with the cue "Color?" or "Background?" respectively. The subjects were then to indicate whether or not the color or the context of the object, respectively, had changed (feature decision). Features were assessed only in order to check whether feature information was in principle available. Again, maximum RT was $3 \mathrm{sec}$ from stimulus onset. The intertrial interval was $2 \mathrm{sec}$ from keypress or expiration of maximum RT. The shift keys were used for both the old-new and the feature decision; the assignment of keys to responses was counterbalanced across subjects to avoid undue lateralization effects in ERPs. Thirty-two subjects (16 per group), all students at Saarland University, took part in this experiment (mean age was $23 / 25$ years, ranging from 19-28/20-36, in the color/context groups, respectively; 10/9 of the subjects were female). They were paid for participation. The ERP data of 3 subjects, 2 in the context and 1 in the color group, had to be excluded due to excessive EEG artifact.

\section{EEG/ERP Recording and Analysis}

EEG was recorded from $63 \mathrm{Ag} / \mathrm{AgCl}$ electrodes using an elastic cap (Electro-Cap International, Eaton, OH). Electrodes were arranged according to the extended 10-20 system. Signals were amplified using an AC coupled amplifier (Brain Amp MR, Brain Products, Munich; time constant, $10 \mathrm{sec}$ ) and referenced to left mastoid, but later rereferenced offline to linked mastoids. The sampling rate was $250 \mathrm{~Hz}$, and a $50-\mathrm{Hz}$ notch filter was applied online. The imped- 
ances of all the electrodes were kept below $10 \mathrm{k} \Omega$, and ocular blinks, as well as vertical and horizontal eye movements, were registered by two electrodes above and below the right eye and by two further electrodes at the outer canthi of both eyes. EOG artifacts were then corrected offline (Gratton, Coles, \& Donchin, 1983). Before averaging, trials containing artifacts (lowest allowed activity in successive 100 -msec intervals, $\pm 0.5 \mu \mathrm{V}$; maximum amplitude in the recording epoch, $\pm 100 \mu \mathrm{V}$; maximum voltage step between two successive sampling points, $50 \mu \mathrm{V}$; maximum difference between any two sampling points within an epoch, $150 \mu \mathrm{V})$ were excluded $(6.9 \%$ of object decision trials). Digital bandpass filtering was applied between 0.1 and $20 \mathrm{~Hz}$. Then ERPs were calculated by time-locked signal averaging, using the time window from -200 to $1,300 \mathrm{msec}$ relative to stimulus onset. Data were baseline corrected using the $200 \mathrm{msec}$ before stimulus onset, in which none of the compared conditions differed.

Object decision ERPs were calculated for both groups separately. Only trials with both a correct old-new response and a correct subsequent feature decision (for old items) were included in the analysis. There were too few trials available for contrasting object hits with versus without a correct subsequent feature decision. This procedure resulted in the following conditions (mean numbers of trials for color-group/context-group in parentheses): same hits (30/29), different hits (28/26), and correct rejections (69/73). The minimum number of trials for inclusion in a grand average was 16. Statistical analyses were performed by means of ANOVAs on mean voltages in several different time windows (details below). Nine regions of interest (ROIs) constituting a three $\times$ three matrix were defined. ROIs and respective electrodes were the following: left-frontal, AF3, F5, F7; mid-frontal, Fz, F1, F2; left-central, C5, CP5, T7; mid-central, Cz, C1, C2; left-posterior, P5, P7, PO7; mid-posterior, $\mathrm{Pz}, \mathrm{P} 1, \mathrm{P} 2$; and the respective right counterparts to left-sided regions and electrodes. The resulting three-level factors of anterior-posterior (AP) and laterality (Lat) were used in all the analyses. ANOVA interactions of particular interest - indexed by a subscript E in the ERP results tables - were confirmed by way of additional single-electrode analyses (using one electrode from each ROI: $\mathrm{F} / \mathrm{C} / \mathrm{P} 5, \mathrm{~F} / \mathrm{C} / \mathrm{Pz}, \mathrm{F} / \mathrm{C} / \mathrm{P} 6)$; the results coincided in all cases. The Greenhouse-Geisser correction for nonsphericity was applied (Greenhouse \& Geisser, 1959); original degrees of freedom, together with respective $\varepsilon$ values and corrected $p$ values, will be reported in the following. As a result of our hypotheses, follow-up planned comparisons were calculated. Specific (maximal) $p$ values will be given for these comparisons.

\section{Results and Discussion \\ Behavioral Results and Discussion \\ Object decision. Accuracy and RT data are depicted in} Figure 2. The accuracy data show that performances were generally very good. ${ }^{3}$ The subjects were able to recognize almost every object that had been part of the study set (see the left-hand side of Figure 2). Differing from Figure 2, accuracy analyses were performed on performance $(P r)$ scores (hit - false alarm rates; cf. Snodgrass \& Corwin, 1988), since these are a better indication of true performance levels. Performance in all the conditions and blocks was well above chance [all $t \mathrm{~s}(15 / 31)>20.48, p \mathrm{~s}<.001]$. In a $2 \times 2 \times 2$ ANOVA with the factors of block ( 1 or 2$)$, condition (same or different), and group (color or context), there was a significant interaction of condition and group $\left[F(1,30)=11.02, M S_{\mathrm{e}}=0.02, p=.002\right]$, indicating worse performance for color-different items (.88), as compared with the other conditions (.91-.92). Of course, though, this effect has to be interpreted with caution due to reduced variance caused by near-to-ceiling performances. Post hoc contrasts confirmed that same and different performance differed in the color group $[F(1,30)=15.13$, $p<.001]$, but not in the context group $(F<1)$. Although there was a main effect of block $\left[F(1,30)=4.33, M S_{\mathrm{e}}=\right.$ $0.03, p<.05]$, indicating slightly improved performance in Block 2, there were no interactions (all $\left.F_{\mathrm{S}}<1.2\right)$. There was a tendency toward a more liberal response bias (calculated as $B \mathrm{r}=$ false alarm rate $/(1-P r) ;{ }^{4}$ cf. Snodgrass \& Corwin, 1988$)$ in the color group (.55 vs. .38), but this was not significant across blocks $[F(1,30)=3.88, p>.05]$.

The corresponding analysis of mean RTs, including correct rejections - a block $\times$ condition (same, different, or new) $\times$ group ANOVA — revealed a marginally significant interaction between condition and group $[F(2,60)=2.56$, $p<.1$, alongside a main effect of condition $[F(2,60)=$ 9.84, $p<.001]$. Post hoc tests indicated that different hits differed from both same hits and correct rejections in the color group (both $F \mathrm{~s}>4.55$, both $p \mathrm{~s}<.05$ ), whereas in

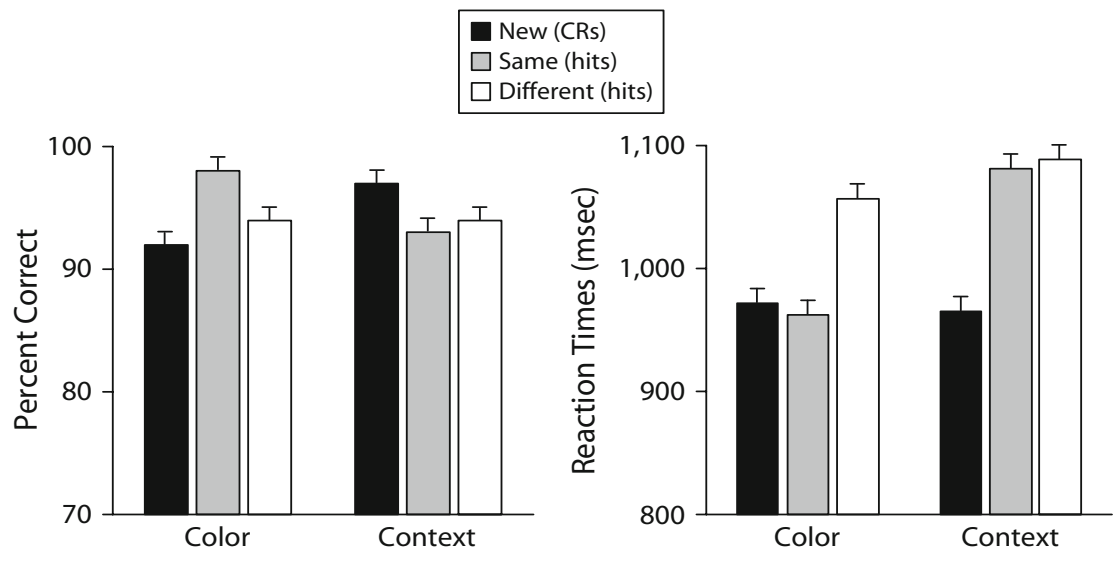

Figure 2. Object (old-new) decision data, Experiment 1: Percent correct (left-hand side) and mean reaction times in milliseconds (right-hand side) for all correct responses as a function of item status. CRs refers to correct rejections; error bars indicate within-subjects standard errors of the means. 


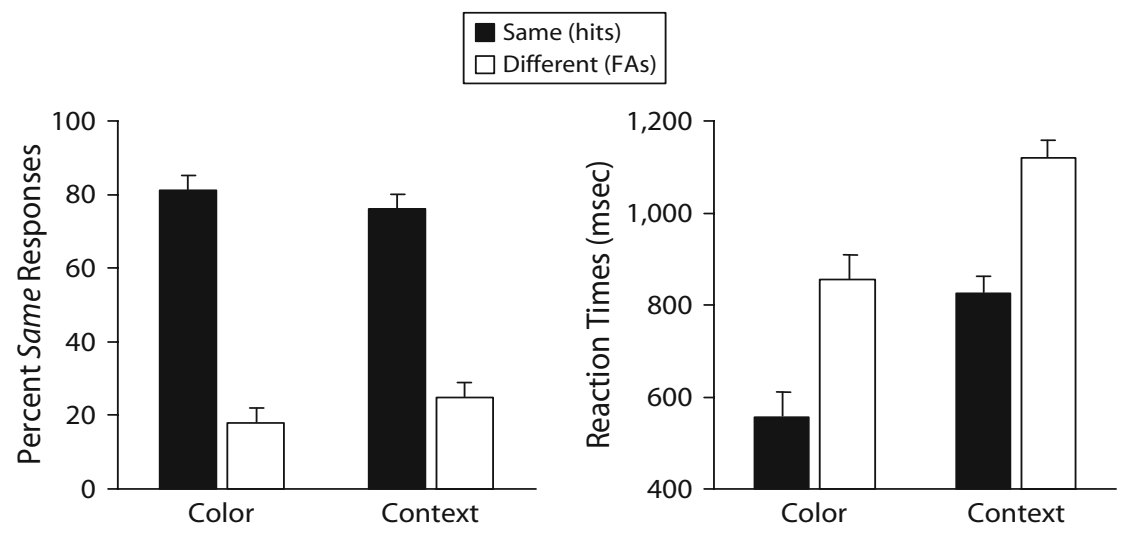

Figure 3. Feature decision data, Experiment 1: Percentages of same responses (left) and mean reaction times (right) as a function of item status; FAs refers to false alarms; error bars indicate within-subjects standard errors of the means.

the context group, correct rejections differed from both kinds of hits (both $F \mathrm{~s}>7.56$, both $p \mathrm{~s}<.05$ ).

Restricting this analysis to hits, given the experimental hypotheses, revealed a significant condition $\times$ group interaction $\left[F(1,30)=6.00, M S_{\mathrm{e}}=7,293, p<.05\right.$; see the right-hand side of Figure 2]. This was due to a benefit for identical repetitions in the color group; that is, colorsame objects were recognized more quickly than colordifferent ones, even though color was not relevant for the old - new decision $[962$ vs. $1,057 \mathrm{msec} ; F(1,30)=19.96$, $p<.001]$. In contrast, context manipulation had no effect on RTs $(1,081$ vs. $1,089 \mathrm{msec} ; F<1.01)$. Again, there was a main effect of block, indicating that the subjects became faster with time, but this interacted neither with condition nor with group (all $F \mathrm{~s}<1.41, p \mathrm{~s}>.24$ ).

These findings are relevant, however, only if context was indeed integrated in the first place. Therefore, it has to be ruled out that context manipulations might have not affected the object decision simply because the subjects had not associated objects with their contexts. This question was addressed by analyzing the feature decision data, depicted in Figure 3.

Feature decision. In order to be able to calculate $\mathrm{Pr}$ scores, we focused analysis on same responses in the feature decision, referring to same responses to same items as hits and same responses to different items as false alarms. The difference between hit and false alarm rates indicates that feature-oriented learning did indeed take place. The difference in conditional relative frequencies between same (hits) and different trials (false alarms) was significant and, equally important, of about the same size for both groups [.81 vs. . 18 in the color group, $F(1,30)=$ $119.78, M S_{\mathrm{e}}=0.03, p<.001 ; .76$ vs. .25 in the context group, $F(1,30)=79.70, M S_{\mathrm{e}}=0.03, p<.001$; see the left-hand side of Figure 3]. There was no significant difference in discrimination scores - calculated as the difference between hits (to identical items) and false alarms (to changed items) - between groups $[P r$ score, .64 vs. .52; $t(30)=1.43, p=.16]$. This means that the association of object and feature information was equally successful in both groups. In both cases, feature information was inte- grated into a memory representation. There was no difference in group bias $(B \mathrm{r}$ score, .50 vs. $.51 ; t<1)$.

As far as RTs are concerned, two main effects were apparent: False alarms were slower than hits [averages of 988 vs. $691 \mathrm{msec} ; F(1,30)=58.75, p<.001]$, and feature decisions in the context group took longer than those in the color group [ $825 \mathrm{vs} .556 \mathrm{msec}$ for hits, $1,120 \mathrm{vs}$. $856 \mathrm{msec}$ for false alarms; $F(1,30)=8.28, p<.01$; see the right-hand side of Figure 3].

\section{ERP Results and Discussion}

Stimulus-locked ERPs elicited by old items with both a correct object and feature decision and by correctly rejected new items are shown in Figure 4 and 5, for both groups, respectively. ${ }^{5}$ Topographic maps are shown in Figure 6 and 7.

Old items elicited more positive-going waveforms, starting at around $250 \mathrm{msec}$ post-stimulus-onset, especially at frontocentral electrodes. This effect corresponds to the well-studied FN400 effect, often associated with familiarity processes, in terms of onset timing and topography (Mecklinger, 2000). It is apparent in both groups, although it seems to be diminished for color-different items. From about $450 \mathrm{msec}$ onward, old items elicited more positivegoing waveforms mainly over centroparietal electrodes. This effect matches well with the LPC effect often associated with recollection (Mecklinger, 2000). Again, both groups show this effect, although it is reduced in colordifferent trials. In the context group, this effect also extends to frontal electrode sites, which it can be assumed reflects activity of an additional frontal cortical source. ${ }^{6}$ Third, old item potentials remained more positive until well beyond $1,000 \mathrm{msec}$, especially at frontal and frontopolar electrodes, particularly in the context group.

Analyses were performed in the following manner. On the basis of the literature and visual inspection of the data, segments were divided into two time windows (250-450 msec and 450-700 msec), corresponding to the old-new effects mentioned above. In these time windows, we then contrasted all the conditions by way of repeated measures ANOVAs: new versus same, new versus different, and same versus different. 

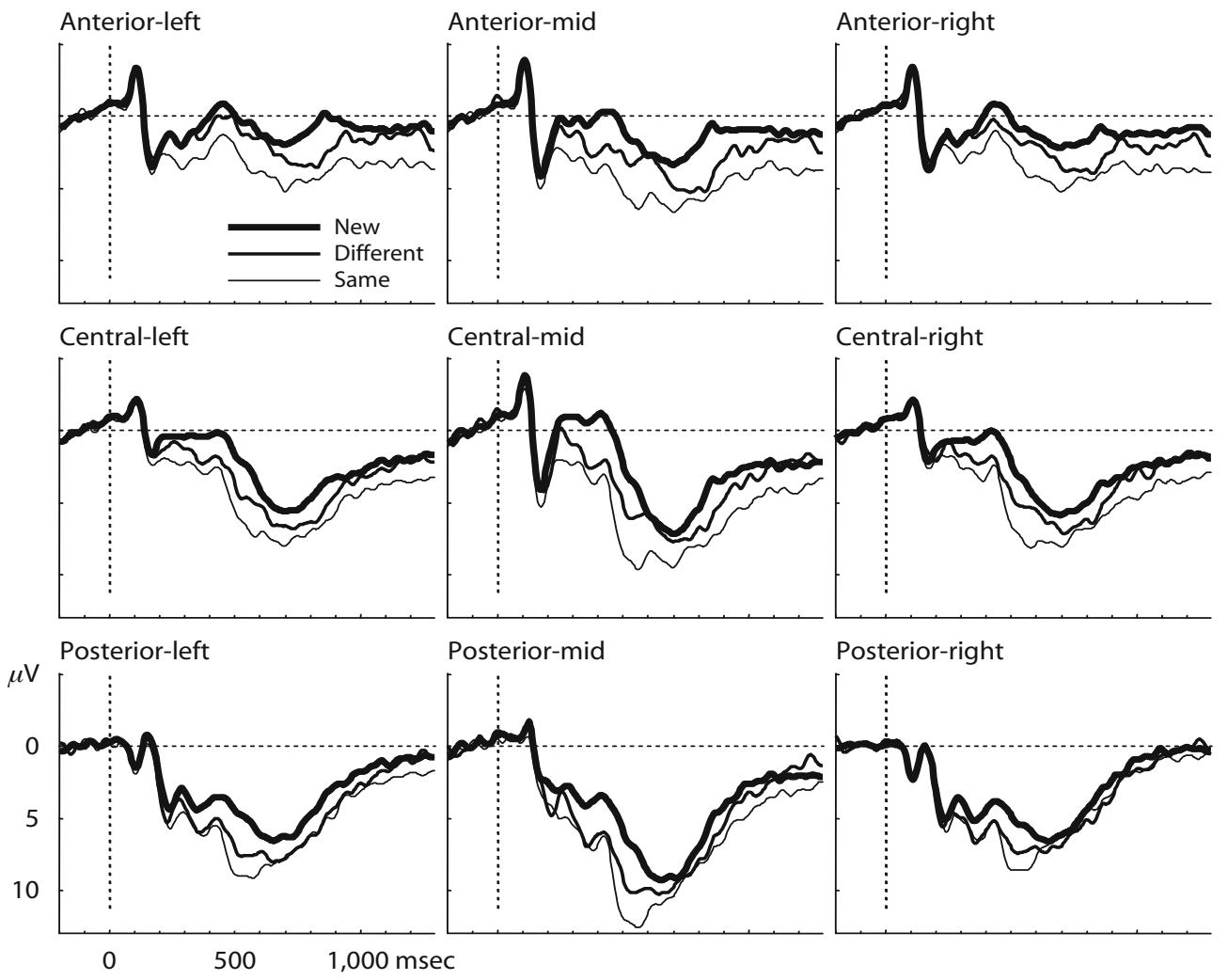

Figure 4. Topographically arranged (regions of interest) grand average ERP data from the object (old-new) decision, Experiment 1, color group. All artifact-free trials with both a correct object and a correct subsequent feature judgment are included. Time scaling ranges from -200 to $1,300 \mathrm{msec}$ post-stimulus-onset. Positive deflections are displayed downward.

Bar graphs displaying early mid-frontal and later posterior old-new effects are shown in Figure 8.

First, we analyzed the data of Time Window 1 (250$450 \mathrm{msec}$ ) across groups to assess familiarity processing. The same analyses were then performed for both groups separately (for the ANOVA results, see Table 1). The most important findings are the significant condition $X$ AP $\times$ group interaction in the new-different (and samedifferent) analysis and the condition $\times$ AP interaction in the same-different analysis of the color group.

After these coarse analyses, given the significant condition $\times$ group interactions, planned comparisons were calculated for both groups separately (note that this was also done across groups, with results coinciding unless otherwise indicated).

In the color group, there was a broad old-new effect for same repetitions at all ROIs (all $F \mathrm{~s}>8.99$, all $p \mathrm{~s}<.01$ ). For different repetitions, the effect was mainly significant at mid-central and mid-posterior ROIs $(F>10.27, p<$ $.007)$, but not at the mid-frontal ROI $(F=3.02, p=.10$; note, however, that this effect was significant in an acrossgroup planned comparison: $F=4.36, p<.05)$. The theoretically interesting difference between the two old conditions was significant at the mid-frontal ROI $(F=4.62$, $p<.05)$.

In the context group, planned comparisons revealed an old-new effect for same trials at all midline ROIs $(F>$
$6.86, p<.02)$. For different repetitions, the effect was significant at mid-frontal and mid-central sites $(F>10.67$, $p<.007)$. As was indicated by an ANOVA, there were no differences between the two old conditions (note that there were no significant effects in post hoc contrasts either).

Next, we focused on Time Window 2 (450-700 msec), again analyzing the data across groups first, then separately for both groups (see Table 2). Again, the most important findings are the significant condition $\times$ AP $\times$ group interaction in the new-different (and same-different) analysis and the condition $\times$ Lat interaction in the same-different analysis of the color group.

Focusing on the color group, old-new effects for same repetitions were significant at all ROIs (all $F$ s $>10.94$, all $p \mathrm{~s}<.006) .{ }^{7}$ For different repetitions, effects were reliable primarily at the left-posterior ROI $(F=16.36, p=$ .001 ; left-central and mid- and right-posterior significant at $F>6.34, p<.03)$. Same and different conditions differed significantly at central ROIs (all $F \mathrm{~s}>9.73$, all $p \mathrm{~s}<$ $.008)$, but also at left- and mid-frontal, as well as midposterior, ROIs (all $F \mathrm{~s}>5.89$, all $p \mathrm{~s}<.03$ ). The difference at the left-posterior ROI was marginally significant $(F=3.38, p=.09)$.

In the context group, old-new effects for both old conditions occurred at all ROIs except the right-posterior one (all $F \mathrm{~s}>5.32$, all $p \mathrm{~s}<.04)$. There were no differences between the two old conditions. 


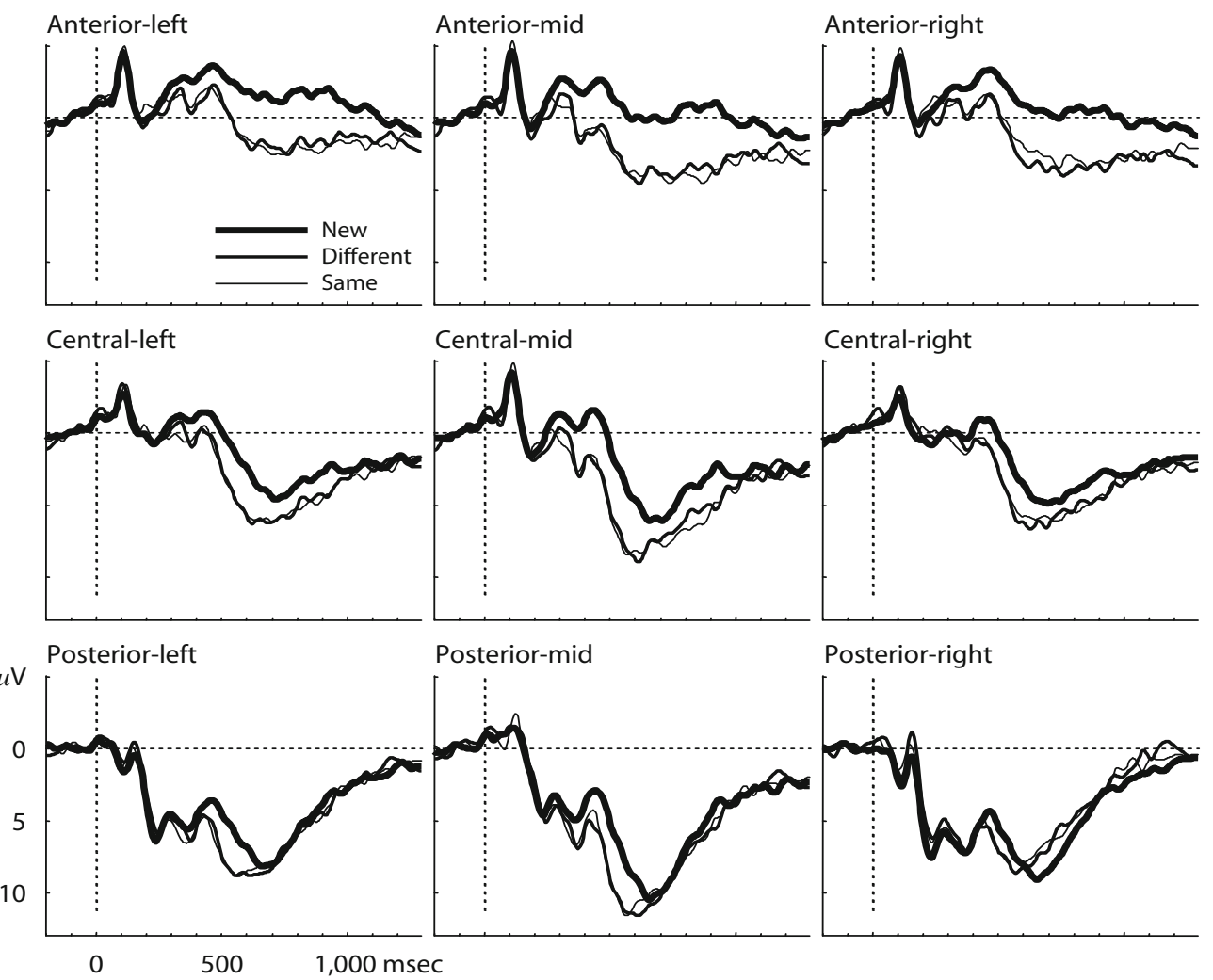

Figure 5. Topographically arranged (regions of interest) grand average ERP data from the object (old-new) decision, Experiment 1, context group. All artifact-free trials with both a correct object and a correct subsequent feature judgment are included. Time scaling ranges from -200 to 1,300 msec post-stimulus-onset. Positive deflections are displayed downward.

Looking at the relationship between behavioral performance and electrophysiological measures in the color group, we found the interesting result that the congruency effects on RTs, on the one hand, and on the early mid- frontal ERP component, on the other, correlated $(r=.45$, $\left.p<.05_{\text {one-sided }}\right)$. That is, the stronger the increase in RTs for color-different items, as compared with same items, the larger the reduction of the FN400 old-new effect at the

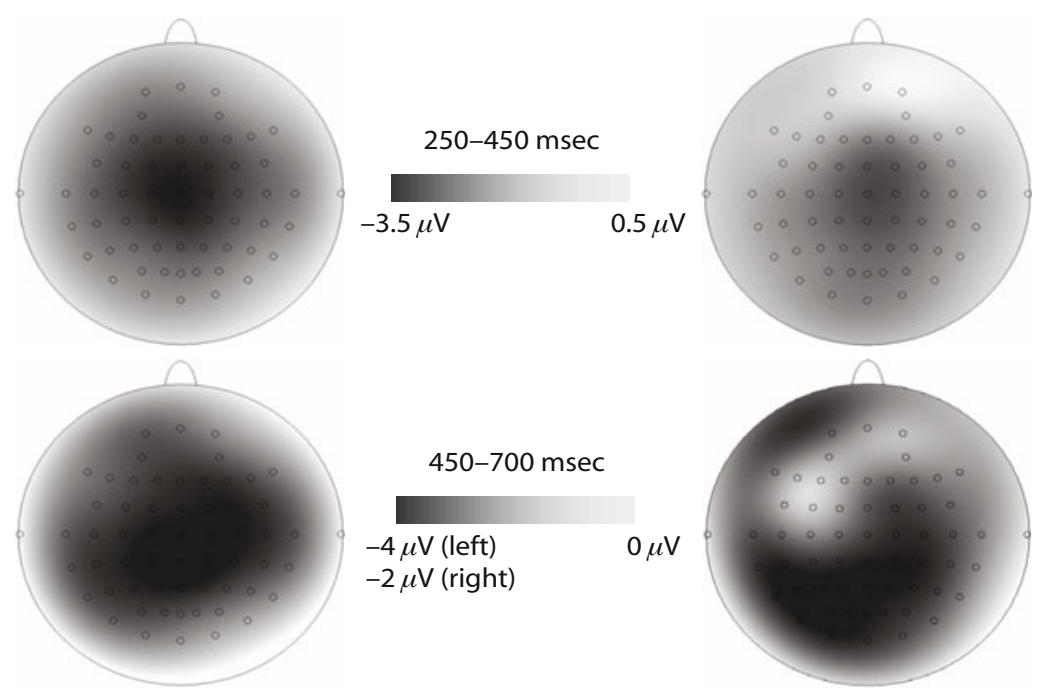

Figure 6. Topographic ERP maps depicting the differences for correct rejections - same hits (left) and correct rejections - different hits (right) in the color group, Experiment 1. 


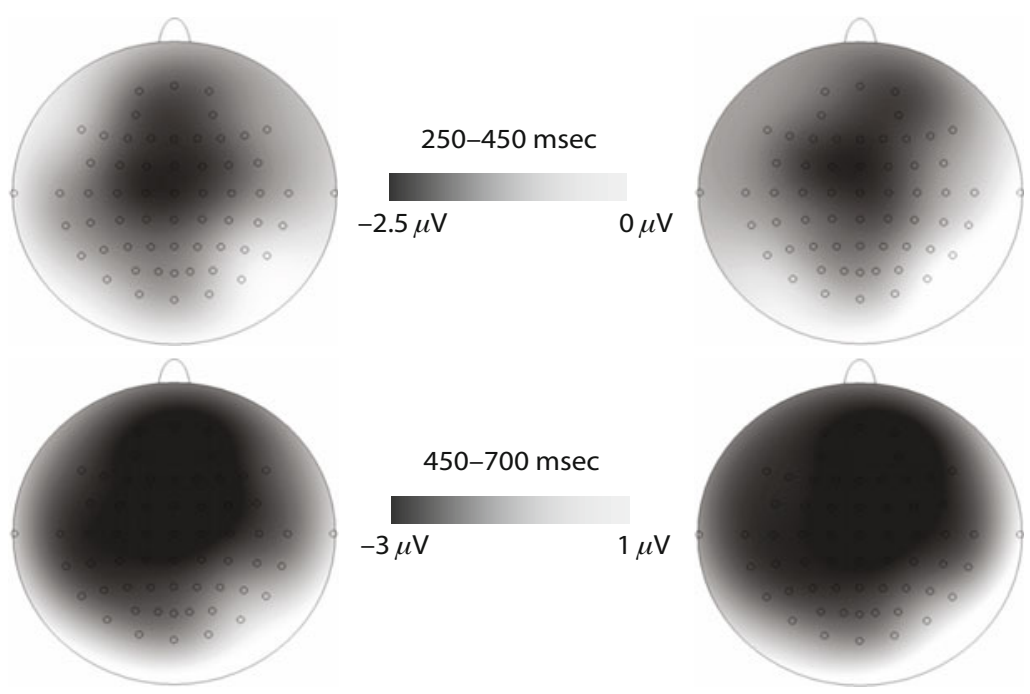

Figure 7. Topographic ERP maps depicting the differences for correct rejections - same hits (left) and correct rejections - different hits (right) in the context group, Experiment 1.

midfrontal ROI. The respective correlation with the later posterior effect was not significant (irrespective of the ROI used for analysis: left-posterior, left-central, or midcentral), the correlation being highest for the left-posterior $\mathrm{ROI}\left(r=.38, p>.05_{\text {one-sided }}\right)$.

Taken together, the subjects in the context group showed no effects of the study-test manipulation, although context information was available (as indicated by feature decision performance). Presumably, whereas the relevant intrinsic information was supplied rather effortlessly in the color group, there was a higher need for controlled retrieval processes when extrinsic information had to be integrated (i.e., in the context group). To further clarify this matter, we additionally analyzed data from frontopolar electrodes (shown in Figure 9) in an additional late time window (800-1,200 msec), based on visual inspection and prior studies reporting late frontal activity when there was need for source reintegration (e.g., Schloerscheidt \& Rugg, 2004; Van Petten et al., 2000; Wilding \& Rugg, 1996).
In this late time window, for the analysis of both new versus same and new versus different, the condition $\times$ Lat $\times$ group interaction was marginally significant $[F(2,54)=$ $3.66 / 3.23, p=.054 / .058, \varepsilon=.65 / .82]$. The comparison of the two old conditions yielded no effects $(F<1.2)$. Post hoc contrasts showed that in the color group, there were old-new effects at the left-frontopolar electrode for both old conditions $(F>6.41, p<.02)$. In the context group, however, there were significant old-new effects at all frontopolar electrodes for both old conditions (same, effects between $F=5.04, p=.03$, and $F=12.84, p=$ .001 ; different, effects between $F=7.83, p=.01$, and $F=13.09, p=.001)$.

\section{EXPERIMENT 2}

\section{Design and Hypotheses}

Experiment 1 was successful in demonstrating that intrinsic manipulations affect both behavioral and ERP
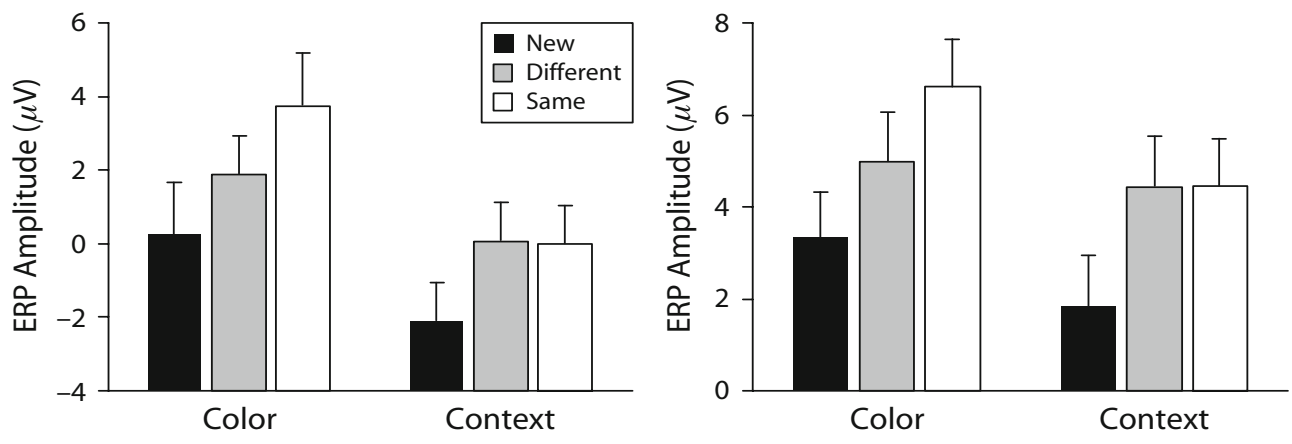

Figure 8. Mean ERP voltages from correctly assessed object (old-new) decision trials (with correct subsequent feature decision; Experiment 1) as a function of condition. Data from the mid-frontal region of interest (ROI) in Time Window $1(250-450 \mathrm{msec})$ are depicted on the left; data from the left-central ROI in Time Window $2(450-700 \mathrm{msec})$ are depicted on the right. Error bars indicate within-subjects standard errors of the means. 
Table 1

Anterior-Posterior (3) $\times$ Laterality (3) $\times$ Condition (2) [X Group (2)] ANOVAs, Time Window 1, Experiment 1

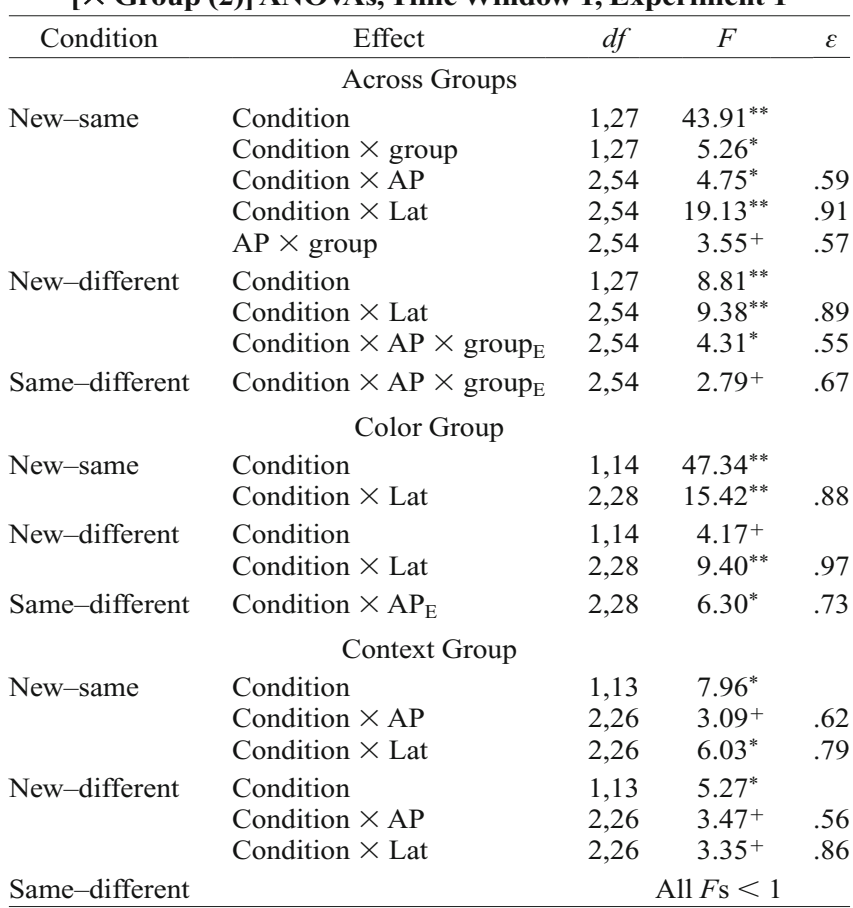

Note-ANOVA interactions of particular interest, indexed by a subscript $\mathrm{E}$, were confirmed by way of additional single-electrode analyses (see Method for details). AP, anterior-posterior; Lat, laterality. ${ }^{+} p<.1$. ${ }^{*} p<.05 . \quad{ }^{* *} p<.01$.

data, as was expected. Moreover, contextual manipulations did not affect the midfrontal old-new effect, exactly as predicted by our model. However, there is another possible interpretation of the data. For instance, one could assume that context has no influence on the FN400 effect only because context retrieval is more effortful than color retrieval. Perhaps, during object processing, subjects do perform an unneeded task if it is easy to do, but not if it is effortful. Rather, the effortful task is postponed to the moment it is really needed. This would mean that the lack of context effects on the familiarity component may only be a matter of different strategies: If context is directly and immediately task relevant and, therefore, the effort of retrieval is not needless, subjects will access this information early, and context will then also influence the early familiarity component. In contrast, we argue that the two features are retrieved by different processes. Color features are provided by object tokens and context features by episodic tokens, and this difference cannot be overcome by strategic decisions. If the familiarity signal results from access to object token and context information is not provided by this unit, we still predict that the familiarity component is not influenced by a changed context, even if it is directly relevant and even if it can be retrieved. Thus, in Experiment 2, we again manipulated context, but now we used an exclusion, instead of an inclusion, task, thereby putting context information into the focus of attention and making it directly task relevant. If, in this case, the FN400 familiarity effect were still unaffected by contextual manipulation, this would be strong evidence for our notion that contextual features are not bound in the object token. In contrast, we expected an influence of the contextual manipulation on the LPC effect. Since context-different objects now were to be rejected, context had to be processed in order to solve the task (we knew from the feature decision in Experiment 1 that this information is available), and the mismatch of context information should thus influence the LPC recollection effect. Thus, a differential influence of the contextual manipulation on the FN400 (no modulation) and LPC old-new effects (modulation) was expected in the exclusion task in Experiment 2.

\section{Method}

Sixteen subjects, all students at Saarland University, took part in this experiment (mean age was 22 years, ranging from 18 to $29 ; 10$ of the subjects were female). They were paid for participation. Apart from instructions (and thus, of course, no more additional feature decision), all further details concerning design, procedure, and analysis were exactly the same as those in the context condition in Experiment 1, with the following minor exceptions. Instead of an ElectroCap, a 63-channel Easycap (Easycap GmbH, Herrsching-Breitbrunn, Germany) was used, after hardware had been exchanged in the whole laboratory. Related to this, ROIs were changed, since the most lateral electrodes (columns 7 and 8) in this experiment (and others) showed virtually no old-new effects. Thus, lateral ROIs were now made up of

Table 2

Anterior-Posterior (3) $\times$ Laterality (3) $\times$ Condition (2) $[\times$ Group (2)] ANOVAs, Time Window 2, Experiment 1

\begin{tabular}{|c|c|c|c|c|}
\hline Condition & Effect & $d f$ & $F$ & $\varepsilon$ \\
\hline \multicolumn{5}{|c|}{ Across Groups } \\
\hline \multirow[t]{4}{*}{ New-same } & Condition & 1,27 & $39.64^{* *}$ & \\
\hline & Condition $\times$ AP & 2,54 & $4.03^{*}$ & .59 \\
\hline & Condition $\times$ Lat & 2,54 & $9.77^{* *}$ & .95 \\
\hline & Condition $\times$ AP $\times$ Lat & 2,54 & $3.34^{*}$ & .75 \\
\hline \multirow[t]{4}{*}{ New-different } & Condition & 1,27 & $14.84^{* *}$ & \\
\hline & Condition $\times$ Lat & 2,54 & $3.52^{*}$ & .85 \\
\hline & Condition $\times \mathrm{AP} \times$ Lat & 4,108 & $4.73^{* *}$ & .75 \\
\hline & Condition $\times \mathrm{AP} \times$ group $_{\mathrm{E}}$ & 2,54 & $5.42^{*}$ & .57 \\
\hline \multirow[t]{3}{*}{ Same-different } & Condition & 1,27 & $4.67^{*}$ & \\
\hline & Condition $\times$ Lat & 2,54 & $3.23^{*}$ & .97 \\
\hline & Condition $\times$ group $_{\mathrm{E}}$ & 1,27 & $6.43^{*}$ & \\
\hline \multicolumn{5}{|c|}{ Color Group } \\
\hline New-same & Condition & 1,14 & $28.68^{* *}$ & \\
\hline & Condition $\times$ Lat & 2,28 & $6.69^{*}$ & .67 \\
\hline New-different & Condition & 1,14 & $3.48^{+}$ & \\
\hline \multirow[t]{2}{*}{ Same-different } & Condition & 1,14 & $8.64^{*}$ & \\
\hline & Condition $\times$ Lat & 2,28 & $4.43^{*}$ & .92 \\
\hline \multicolumn{5}{|c|}{ Context Group } \\
\hline \multirow[t]{3}{*}{ New-same } & Condition & 1,13 & $13.18^{* *}$ & \\
\hline & Condition $\times$ AP & 2,26 & $5.30^{*}$ & .62 \\
\hline & Condition $\times$ Lat & 2,26 & $4.16^{*}$ & .78 \\
\hline \multirow[t]{4}{*}{ New-different } & Condition & 1,13 & $13.98^{* *}$ & \\
\hline & Condition $\times$ AP & 2,26 & $6.29^{*}$ & .57 \\
\hline & Condition $\times$ Lat & 2,26 & $2.92^{+}$ & .83 \\
\hline & Condition $\times$ AP $\times$ Lat & 4,52 & $3.87^{*}$ & .61 \\
\hline Same-different & & \multicolumn{3}{|c|}{ All $F_{\mathrm{S}}<1$} \\
\hline
\end{tabular}

Note-ANOVA interactions of particular interest, indexed by a subscript E, were confirmed by way of additional single-electrode analyses (see Method for details). AP, anterior-posterior; Lat, laterality. ${ }^{+} p<.1 . \quad{ }^{*} p<.05 . \quad{ }^{* *} p<.01$. 


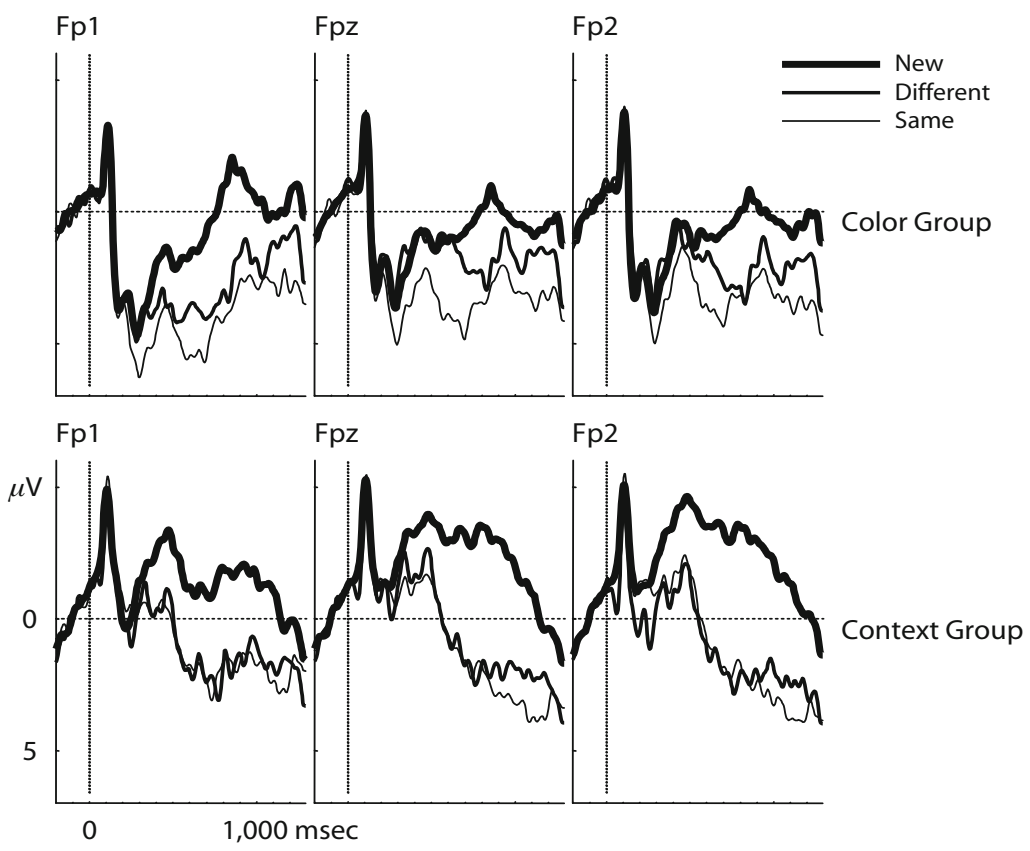

Figure 9. ERPs from frontopolar electrodes, Experiment 1. All artifact-free trials with both a correct object and a correct subsequent feature judgment are included. Time scaling ranges from -200 to 1,300 msec post-stimulus-onset. Positive deflections are displayed downward.

the following electrodes: F3, F5, AF3 (anterior); C3, C5, CP5 (central); and P3, P5, CP3 (posterior); and their right-sided counterparts, respectively. Following artifact rejection (elimination of $4 \%$ of the trials), ERPs were calculated to correct responses to same items (mean number of trials: 32), different items (25), and new (76) items, the only difference being that different items now had to be rejected.

\section{Results and Discussion}

\section{Behavioral Results and Discussion}

Accuracy and RT data are shown in Figure 10. The subjects were almost perfect in rejecting new items (rate, .98 correct), and both rates of hits to same items and correct rejections of different items were reliably above chance [both $t \mathrm{~s}(15)>6.18, p<.001]$. An ANOVA including a block factor revealed only a main effect of condition $\left[F(2,30)=103.85, M S_{\mathrm{e}}=0.01, p<.001\right]$, and follow-up contrasts signaled reliable differences between all three conditions [all $\left.F_{\mathrm{S}}(1,15)>43.97, p<.001\right]$; that is, there were more correct rejections of new items than there were hits (rate, .83), and there were more hits than correct rejections of different items (rate, .65). In addition, $P r$ scores were calculated on the basis of false alarms to different items (rate, .31; neglecting almost perfect rejection of new items). Mean $\operatorname{Pr}$ was .52, which

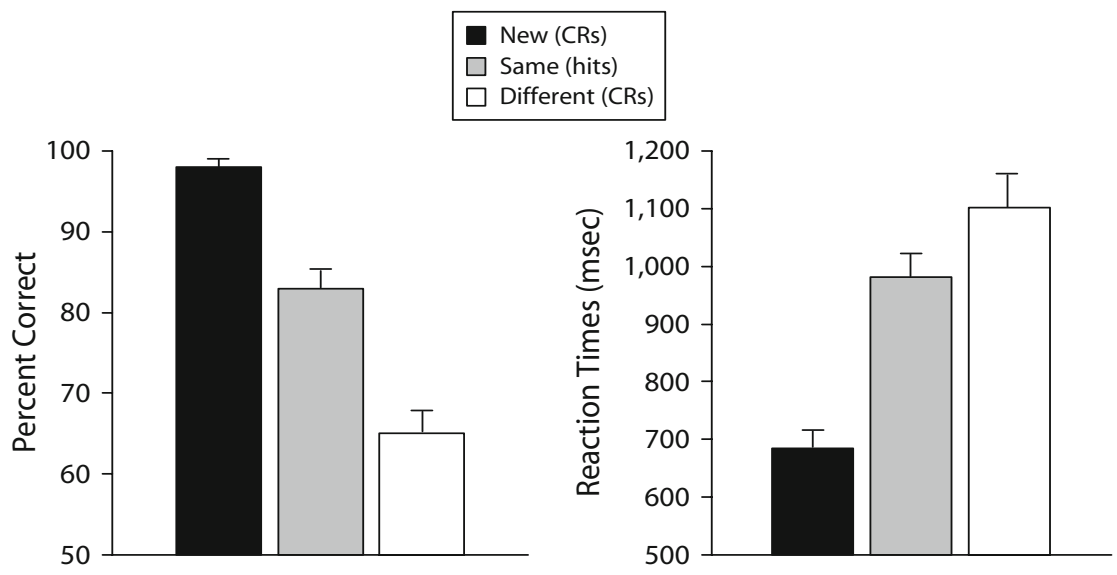

Figure 10. Recognition data, Experiment 2: Percent correct (left-hand side) and mean reaction times in milliseconds (right-hand side) for all correct responses as a function of item status. CRs refers to correct rejections; error bars indicate withinsubjects standard errors of the means. 


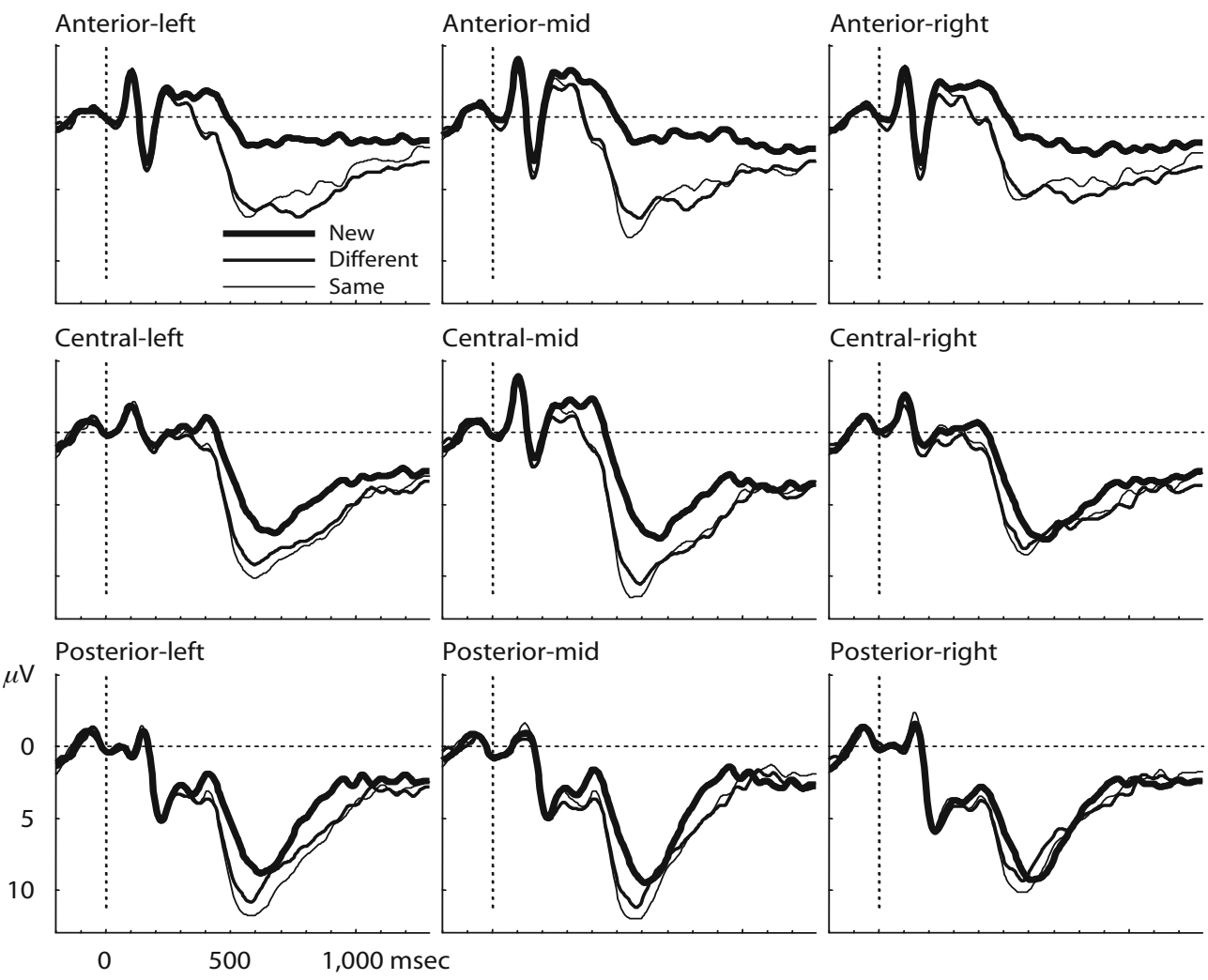

Figure 11. Topographically arranged (regions of interest) grand average ERP data from Experiment 2 . All artifact-free trials with correct responses are included. Time scaling ranges from -200 to 1,300 msec post-stimulus-onset. Positive deflections are displayed downward.

differed significantly from chance performance $[t(15)=$ $16.28, p<.01]$.

RT analysis was performed in the same way. An ANOVA including a block factor revealed only a main effect of condition $\left[F(2,30)=84.10, M S_{\mathrm{e}}=17,130, p<.001\right]$. Post hoc contrasts showed that all three conditions differed from each other (all $F \mathrm{~s}>13.72, p<.01$ ); that is, correct rejections of new items were fastest (684 $\mathrm{msec})$, followed by hits $(981 \mathrm{msec})$ and correct rejections of different items $(1,102 \mathrm{msec})$. For sake of completeness, the mean latency of false alarms to different items was $1,110 \mathrm{msec}$. Thus, the RT data mirrored the accuracy findings.

\section{ERP Results and Discussion}

Stimulus-locked ERPs elicited by items correctly responded to are shown in Figure 11. Topographic maps are shown in Figure 12.

Visual inspection suggests that old items elicited more positive-going waveforms, starting at around $300 \mathrm{msec}$ post-stimulus-onset, especially at frontal sites. Later in time, the effect remains largest at frontal sites while extending more strongly to left- and mid-posterior sites, as well. From about $500 \mathrm{msec}$, correct responses to same and different items differ, especially at left-posterior sites. Statistical analyses were again carried out by way of repeated measures ANOVAs in selected time windows. After visual inspection, these were set to the standard values of 300-500 msec and 500-800 msec.
First, we analyzed data from Time Window 1 in order to assess familiarity processing. Table 3 shows the ANOVA results. Most important, whereas overall old-new effects were reliable, there were no effects in the comparison of the two old conditions.

Planned comparisons showed that the old-new effect for same hits, although largest at the mid-frontal ROI, was significant at all ROIs (all $F \mathrm{~s}>5.06, p<.04$ ). Likewise, for different items, the old-new effect was reliable at all ROIs (all $F_{\mathrm{S}}>9.17, p<.01$ ), except the right-posterior one. Despite the nonsignificant ANOVA comparing the two old conditions, planned comparisons were calculated, which substantiated the null effect (all $F$ s $<1$ ).

The ANOVA results for Time Window 2 are displayed in Table 4. Again, old-new analyses yielded reliable results, the most noteworthy finding being, however, the AP $\times$ condition interaction in the comparison of the two old conditions. ${ }^{8}$

In planned comparisons, the old-new effect for same hits was significant at all ROIs (all $F_{\mathrm{S}}>6.73, p<.02$ ), except the right-central and right-posterior ones (all $F \mathrm{~s}<1.92$, $p>.1)$. The old-new effect for correct rejections of new versus different items was significant at all ROIs (all $F$ s $>$ 5.55, $p<.03$ ), excluding right-central, right-posterior, and mid-posterior regions (all $F \mathrm{~s}<2.19, p>.1$ ). Planned comparison of same hits and different correct rejections revealed a significant difference at the theoretically most relevant left-posterior ROI $(F=4.73, p<.05)$. 


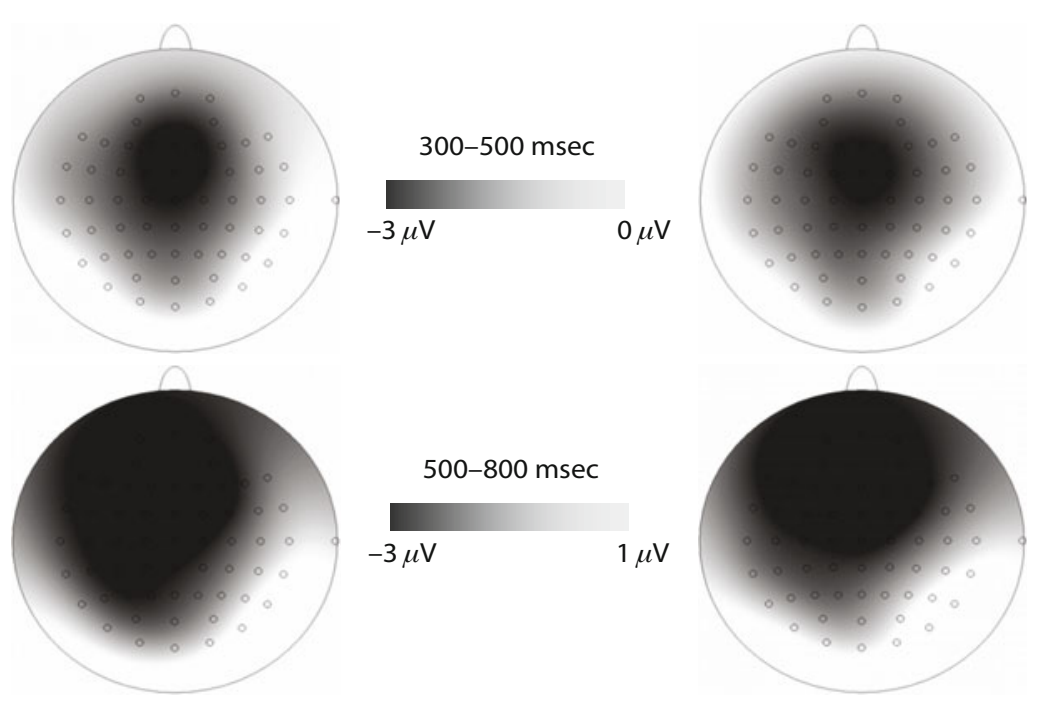

Figure 12. Topographic ERP maps depicting the differences for correct rejections of new items - same hits (left) and correct rejections of new items correct rejections of different items (right) in Experiment 2.

Taken together, there was a frontally focused FN400 old-new effect of equal magnitude for both old conditions in Time Window 1, independent of study-test congruency and even though context was directly task relevant. In Time Window 2, although the broad ${ }^{9}$ old - new effects were reliable for both old conditions, same items elicited a significantly larger left-posterior LPC effect than did different items.

\section{GENERAL DISCUSSION}

The aim of this study was to test whether intrinsic and extrinsic features are differently processed in episodic memory. We therefore manipulated an intrinsic (color; Experiment 1) and an extrinsic (context; Experiments 1 and 2) feature in two recognition experiments. In Experiment 1 , we adopted a sequential test procedure, with an old-new object recognition test, followed by a feature recognition (source memory) test. In the inclusion task, we expected the manipulation of the intrinsic feature to slow down object recognition but expected no such effect for the extrinsic feature. We predicted that both kinds of features themselves, however, could be voluntarily recognized to

Table 3

Anterior-Posterior (3) $\times$ Laterality (3) $\times$ Condition (2) ANOVA Across Groups, Time Window 1, Experiment 2

\begin{tabular}{llrrr}
\hline Condition & \multicolumn{1}{c}{ Effect } & $d f$ & $F$ & $\varepsilon$ \\
\hline New-same & Condition & 1,15 & $17.56^{* *}$ & \\
& Condition $\times$ AP & 2,30 & $8.29^{* *}$ & .69 \\
& Condition $\times$ Lat & 2,30 & $14.58^{* *}$ & .95 \\
& Condition $\times$ AP $\times$ Lat & 4,60 & $3.29^{* *}$ & .69 \\
New-different & Condition & 1,15 & $16.64^{* *}$ & \\
& Condition $\times$ AP & 2,30 & $7.63^{* *}$ & .66 \\
& Condition $\times$ Lat & 2,30 & $13.53^{* *}$ & .82 \\
Same-different & & \multicolumn{3}{c}{ all $F$ s $<1.1$} \\
\hline Note-AP, anterior-posterior; Lat, laterality. & ${ }^{*} p<.05$. & ${ }^{* *} p<.01$.
\end{tabular}

a similar degree. The behavioral results of Experiment 1 confirmed these hypotheses, in line with the behavioral literature. The results imply that the study-test manipulation of an irrelevant intrinsic feature affects object recognition accuracy and RTs, whereas the manipulation of an extrinsic feature does not affect object recognition performance in an inclusion task. Equivalent performance in associative feature recognition across groups demonstrates that this holds true even though both kinds of information had been learned and associated with object information to a comparable degree. ${ }^{10}$ This pattern indicates that it is not a quantitative difference in memory strength underlying the object decision effects, but a more fundamental difference in processing and representation. This makes the retrieval of contextual information a more deliberate process, as compared with the retrieval of intrinsic information, which is supplied rather automatically. Likewise, RTs in the color-same condition are shortest, suggesting that subjects may have no additional memory work to do on these trials. The RTs in the feature decision (i.e., faster responses in the color group) point in the same direction.

Furthermore, we hypothesized that both kinds of manipulations would modulate ERP old-new effects in a distinctive manner. In particular, in Experiment 1, a manipulation of the intrinsic, but not the extrinsic, feature was thought to impact on the frontal old-new effect associated with familiarity. An influence of a color mismatch on the parietal recollection effect was considered possible due to the automatic supply of intrinsic information. On the other hand, if context influences old-new effects at all, it should be the LPC that is affected, since extrinsic information is bound only in the episodic token. However, an influence of context on the parietal effect was nevertheless not expected in Experiment 1, due to inclusion instructions and the model assumption that extrinsic feature retrieval is a controlled and effortful process. In contrast, in Experiment 2 (exclusion task), a context effect on the parietal 
Table 4

Anterior-Posterior (3) $\times$ Laterality (3) $\times$ Condition (2) ANOVA Across Groups, Time Window 2, Experiment 2

\begin{tabular}{clccc}
\hline Condition & \multicolumn{1}{c}{ Effect } & $d f$ & $F$ & $\varepsilon$ \\
\hline New-same & Condition & 1,15 & $16.00^{* *}$ & \\
& Condition $\times$ AP & 2,30 & $11.33^{* *}$ & .65 \\
& Condition $\times$ Lat & 2,30 & $20.71^{* *}$ & .83 \\
& Condition $\times$ AP $\times$ Lat & 4,60 & $3.59^{*}$ & .45 \\
New-different & Condition & 1,15 & $11.93^{* *}$ & \\
& Condition $\times$ AP & 2,30 & $39.39^{* *}$ & .60 \\
& Condition $\times$ Lat & 2,30 & $15.87^{* *}$ & .92 \\
& Condition $\times$ AP $\times$ Lat & 4,60 & $2.39^{+}$ & .59 \\
Same-different & Condition $\times$ AP & 2,30 & $5.65^{*}$ & .92 \\
\hline
\end{tabular}

Note-ANOVA interactions of particular interest, indexed by a subscript E, were confirmed by way of additional single-electrode analyses (see Method for details). AP, anterior-posterior; Lat, laterality. ${ }^{+} p<.1$. ${ }^{*} p<.05 . \quad{ }^{* *} p<.01$.

component was predicted, whereas an influence on the early mid-frontal effect was still precluded. ERP results were in line with these predictions. The intrinsic manipulation modulated both frontal and parietal ERP old-new effects, but there was no effect of the extrinsic manipulation on object recognition ERPs, as long as the feature was not made directly task relevant, in the exclusion task in Experiment 2. In this case, context affected the LPC recollection effect, as was expected, but the FN400 familiarity effect remained uninfluenced by context and can thus be considered acontextual, independent of task relevance (but see Ecker, Zimmer, Groh-Bordin, \& Mecklinger, 2007; Tsivilis et al., 2001). Apparently, the representation subjects address in order to make an old-new decision via familiarity (the object token) includes intrinsic information, but it does not comprise contextual information, even if this information is voluntarily accessible and task relevant.

\section{Intrinsic Feature Manipulation}

The manipulation of object color affected episodic object recognition, as was expected. Although colors were arbitrary and the task was an inclusion task, the subjects were faster and more accurate when items were identically repeated. This replicates previous behavioral results. The effect of this perceptual manipulation on the parietal ERP old-new effect in the color group is also in accordance with previous research (Curran, 2000; Curran \& Cleary, 2003; Ranganath \& Paller, 1999) and is comprehensible in light of the integrative, intentional study (cf. Groh-Bordin et al., 2005, who found no congruency effect on the LPC following incidental study). For instance, associative study instructions will occasionally lead subjects to generate verbal predicates concerning the feature (e.g., "that's a funny color"), which can then potentially be recollected. At test, the automatically arising familiarity signal indicates a mismatch at an early stage of processing. This mismatch signal makes a recheck likely; the system may know that "something is wrong" but may not yet know exactly what. This is where conscious recollection comes into play (cf. the distinction between matching and retrieval; Humphreys, Bain, \& Pike, 1989). In light of the upcoming feature decision, this may have led to a subset of feature decisions being made or prepared during the old-new decision part of the trial, and the reason there is an effect on the LPC only in the color group lies in the automaticity of processing (i.e., color information is involuntarily supplied by the system, context information is not). Thus, intrinsic features may affect recollection, but extrinsic features should not affect familiarity (which is why our hypotheses have allowed for an effect of color change on the LPC but have precluded an effect of context change on the FN400 effect).

The correlation between the effect of study-test congruency on RTs and the FN400 effect indicates that the acceleration of reactions to color-same objects was based on a stronger familiarity signal, underscoring the role of familiarity as a trigger for further (recollective) processing. This also implies that at the data level, familiarity and recollection might not be fully independent; they might be independent processes per se but, nevertheless, operate on representations stemming from the same study episode and, thus, show some dependence on the effect side. This view is in accordance with the ideas of Yonelinas and Jacoby (1995) and also with more neurophysiological models of episodic memory (Aggleton \& Brown, 1999).

The effect of the intrinsic manipulation on the early mid-frontal effect speaks against a view of familiarity as a purely semantic-matching process. Given that slight nonsemantic manipulations have been found to affect only the parietal but not the early mid-frontal old-new effect (Curran, 2000; Curran \& Cleary, 2003), a semantic-matching account of familiarity seems straightforward at first. Our results indicate, however, that perceptual manipulations can indeed affect familiarity and the FN400 effect, depending on the characteristics of the task - for example, the stimulus material used (Groh-Bordin et al., 2005; see also Curran \& Dien, 2003; Curran, Tanaka, \& Weiskopf, 2002; Friedman et al., 2005). We thus agree with the recent notion of Curran, Tepe, and Piatt (2006) that familiarity can be sensitive to both perceptual and conceptual dimensions of similarity. Compatibly, Srinivas and Verfaellie (2000) reported that picture recognition performance of amnesic patients with intact familiarity-based recognition was sensitive to manipulations of perceptual attributes, such as orientation (likewise manipulated in Curran \& Cleary, 2003), and argued convincingly that these effects were based on neither recollection nor priming.

Seemingly, changes of sensory features sometimes do and sometimes do not influence familiarity-based recognition. Familiarity is an ineffective mechanism for detecting slight semantic or sensory stimulus variations (Holdstock et al., 2002; Mayes, Holdstock, Isaac, Hunkin, \& Roberts, 2002). Thus, the change of the familiarity signal and, hence, impairment will be small or even absent if the magnitude of mismatch caused by changed perceptual features is minor, as compared with the magnitude of matching information. However, if the mismatch is substantial and memory access relies on a considerable degree of perceptual processing, familiarity is not purely semantic, but also perceptually specific. Also, note that the effect of a purely perceptual manipulation speaks against the view of the FN400 effect as an index of conceptual priming, as has 
been proposed by Paller (Voss \& Paller, 2006; Yovel \& Paller, 2004; see also Curran et al., 2002; Groh-Bordin et al., 2006; Groh-Bordin et al., 2005).

\section{Extrinsic Feature Manipulation}

Consistent with our expectations, context did not influence episodic object recognition in the inclusion task in Experiment 1. We have pointed out that the reintegration of specific contextual detail in the process of recollection is somewhat controlled and piecemeal. Because context information was not directly relevant for the object old new decision (inclusion task), the subjects were seemingly able to ignore the potentially available (but not automatically supplied) contextual information. Thus, the context manipulation did not even affect RTs or the ERP recollection component. It can be assumed that the higher demand for controlled retrieval and postretrieval processing in the context condition is reflected in the late broad frontal and frontopolar effects (cf. Van Petten et al., 2000; Wilding \& Rugg, 1996). The question of whether these specifically reflect processes of retrieval inhibition, response monitoring, or actual contextual reintegration effort remains speculative and awaits further research.

Yet when the contextual information was made crucial for the subjects' decision in the exclusion task in Experiment 2, contextual manipulation affected the LPC effect associated with recollection, just as our model would predict. Importantly, there was still no effect on the FN400 component in Experiment 2, corroborating our hypotheses that only intrinsic item information affects the early process of familiarity and that contextual integration occurs at a later stage of processing, from about $500 \mathrm{msec}$ onward. This interpretation is supported by the behavioral data of Experiment 2 as well: Correct rejections of new items were made very fast, probably relying mainly on object familiarity, whereas responses requiring context integration were slower, especially when context integration led to a conflicting signal - in the case of familiar items to be rejected due to an altered context (i.e., correct rejections of different items, with lowest accuracy and highest RTs).

Most ERP studies investigating the effects of contextual manipulations did not focus on local context. For instance, Curran and Friedman $(2003,2004)$ manipulated a combination of local and global contextual features. They found a larger late (right-) frontal/frontopolar old-new effect for a rather reconstructive (recollection-like) context test, as compared with a more familiarity-like judgment of temporal distance, but no influence on the mid-frontal FN400 effect. This is broadly consistent with our findings of pronounced frontopolar activation in the context group, as compared with the color group, and of no modulation of the FN400 effect as long as only extrinsic, contextual (be they local or global) features are manipulated.

One of the few ERP studies in which the effects of local contextual manipulations on ERP old-new effects have been examined (Tsivilis et al., 2001) reported an FN400 effect that was sensitive to the unspecific combination of object and context repetition, whereas identically repeated and recombined object-context pairs did not elicit differ- ent waveforms. It can be assumed that the rich and unique landscape scenes used were distinct and salient enough to become "more than context" and achieve the status of familiar objects themselves (thus generating an additional familiarity signal via an object token laid down at encoding; see Ecker et al., 2007; see also Murnane et al., 1999). Yet, as in the present study, Tsivilis et al. found no specific influence of a context manipulation on the ERPs; thus, the assessment of the old-new status of an object can be performed without influence of its context (but see Curran et al., 2006). Our study (Experiment 1) shows that this holds true even if contextual information is potentially available (as demonstrated by the subjects' feature recognition performance) and about to become relevant (in the feature decision immediately following each old-new decision).

\section{Conclusion and Final Thoughts}

Taken together, our data support the model assumptions that, in general, both intrinsic and extrinsic information may modulate recollection, depending on task characteristics, but that only intrinsic features (information bound in a unitized representation) affect familiarity memory, whereas contextual information does not. Future research, however, should aim at more tightly constraining the conditions of unitization. For instance, we had mentioned above that the encoding task has an important influence on retrieval processing: Whereas in Curran and Cleary's (2003) study, encoding was intentional, thus fostering an influence of perceptual manipulation on recollection, Groh-Bordin et al.'s (2005) encoding task was incidental with a strong perceptual focus (items were hard to identify), thus presumably supporting a modulation of familiarity. Likewise, this could be an explanation for a finding apparently contradicting our model: The data of Van Petten, Luka, Rubin, and Ryan (2002) seem to show a larger FN400 effect for identically repeated word pairs than for recombined word pairs (the effect was not formally tested, since it was outside the major focus of the study). The encoding task for the subjects, however, involved combining the mental images of the two words of each study pair, thereby potentially generating a unitized representation. Likewise, it has been pointed out that items of the same type may be easier to unitize or integrate and may thus differ fundamentally from across domain bindings (Mayes et al., 2004; Yonelinas, 2002). Clearly, the focus of the present study is too narrow to conclusively answer the fundamental question of item unitization. Yet we have been able to demonstrate that intrinsic and extrinsic features are differently processed and/or represented in episodic memory, supporting our distinction between object tokens and episodic tokens.

\section{AUTHOR NOTE}

This research was supported by Grant Zi 308/4 to H.D.Z. from the Deutsche Forschungsgemeinschaft within Research Group 448 "Binding: Functional Architecture, Neural Correlates, and Ontogeny." The manuscript was partially written while H.D.Z. was a fellow of the Centre for Advanced Study at the Norwegian Academy of Science and Letters in Oslo. We thank Carina Epple for assistance in preparing the experiment, Thorsten Brinkmann and, especially, Bertram Opitz and Axel Meck- 
linger for fruitful discussions, and the three anonymous reviewers for their many helpful comments and suggestions. Correspondence concerning this article should be addressed to U. K. H. Ecker or H. D. Zimmer, Department of Psychology, Saarland University, P. O. Box 151150, D-66041 Saarbrücken, Germany (e-mail: u.ecker@mx.uni-saarland.de or huzimmer@mx.uni-saarland.de).

\section{REFERENCES}

Aggleton, J. P., \& Brown, M. W. (1999). Episodic memory, amnesia, and the hippocampal-anterior thalamic axis. Behavioral \& Brain Sciences, 22, 425-444.

Asch, S., Ceraso, J., \& Heimer, W. (1960). Perceptual conditions of association. Psychological Monographs, 74, 1-48.

Baddeley, A., Vargha-Khadem, F., \& Mishrin, M. (2001). Preserved recognition in a case of developmental amnesia: Implications for the acquisition of semantic memory? Journal of Cognitive Neuroscience, 13, 357-369.

Cabeza, R. (2006). Prefrontal and medial temporal lobe contributions to relational memory in young and older adults. In H. D. Zimmer, A. Mecklinger, \& U. Lindenberger (Eds.), Handbook of binding and memory: Perspectives from cognitive neuroscience (pp. 595-626). Oxford: Oxford University Press.

Ceraso, J. (1985). Unit formation in perception and memory. In G. H. Bower (Ed.), Psychology of learning and motivation: Advances in research and theory (Vol. 19, pp. 179-210). New York: Academic Press.

Ceraso, J. (1990). Perceptual organization affects both the learning and integration of object properties. In I. Rock (Ed.), The legacy of Solomon Asch: Essays in cognition and social psychology (pp. 113-125). Hillsdale, NJ: Erlbaum.

Cooper, E. E., Biederman, I., \& Hummel, J. E. (1992). Metric invariance in object recognition: A review and further evidence. Canadian Journal of Psychology, 46, 191-214.

Curran, T. (2000). Brain potentials of recollection and familiarity. Memory \& Cognition, 28, 923-938.

Curran, T., \& Cleary, A. M. (2003). Using ERPs to dissociate recollection from familiarity in picture recognition. Cognitive Brain Research, 15, 191-205.

Curran, T., \& Dien, J. (2003). Differentiating amodal familiarity from modality-specific memory processes: An ERP study. Psychophysiology, 40, 979-988.

Curran, T., \& Friedman, W. J. (2003). Differentiating location- and distance-based processes in memory for time: An ERP study. Psychonomic Bulletin \& Review, 10,711-717.

Curran, T., \& Friedman, W. J. (2004). ERP old/new effects at different retention intervals in recency discrimination tasks. Cognitive Brain Research, 18, 107-120.

Curran, T., Tanaka, J. W., \& Weiskopf, D. M. (2002). An electrophysiological comparison of visual categorization and recognition memory. Cognitive, Affective, \& Behavioral Neuroscience, 2, 1-18.

Curran, T., Tepe, K. L., \& Piatt, C. (2006). ERP explorations of dual processes in recognition memory. In H. D. Zimmer, A. Mecklinger, \& U. Lindenberger (Eds.), Handbook of binding and memory: Perspectives from cognitive neuroscience (pp. 467-492). Oxford: Oxford University Press.

Cycowicz, Y. M., Friedman, D., \& Snodgrass, J. G. (2001). Remembering the color of objects: An ERP investigation of source memory. Cerebral Cortex, 11, 322-334.

Duncan, J. (1984). Selective attention and the organization of visual information. Journal of Experimental Psychology: General, 113, 501517.

Duncan, J., Martens, S., \& Ward, R. (1997). Restricted attentional capacity within but not between sensory modalities. Nature, 387, 808810.

Duncan, J., \& Nimmo-Smith, I. (1996). Objects and attributes in divided attention: Surface and boundary systems. Perception \& Psychophysics, 58, 1076-1084.

Düzel, E., Vargha-Khadem, F., Heinze, H. J., \& Mishkin, M. (2001). Brain activity evidence for recognition without recollection after early hippocampal damage. Proceedings of the National Academy of Sciences, 98, 8101-8106.

DüZel, E., Yonelinas, A. P., Mangun, G. R., Heinze, H. J., \& TulvING, E. (1997).Event-related brain potential correlates of two states of conscious awareness in memory. Proceedings of the National Academy of Sciences, 94, 5973-5978.

Ecker, U. K. H., Groh-Bordin, C., \& Zimmer, H. D. (2004). Electrophysiological correlates of specific feature binding in remembering: Introducing a neurocognitive model of human memory. In A. Mecklinger, H. D. Zimmer, \& U. Lindenberger (Eds.), Bound in memory: Insights from behavioral and neuropsychological studies (pp. 159193). Aachen, Germany: Shaker.

Ecker, U. K. H., Zimmer, H. D., Groh-Bordin, C., \& Mecklinger, A. (2007). Context effects on familiarity are familiarity effects of context-An electrophysiological study. International Journal of Psychophysiology, 64, 146-156.

Engelkamp, J., Zimmer, H. D., \& De Vega, M. (2001). Pictures and words in memory: The role of visual-imaginal information. In M. Denis, C. Cornoldi, R. H. Logie, M. de Vega, \& J. Engelkamp (Eds.), Imagery, language and visuo-spatial thinking (pp. 59-80). Hove, U.K.: Psychology Press.

Friedman, D., Cycowicz, Y. M., \& Bersick, M. (2005). The late negative episodic memory effect: The effect of recapitulating study details at test. Cognitive Brain Research, 23, 185-198.

Friedman, D., \& JoHnSON, R., JR. (2000). Event-related potential (ERP) studies of memory encoding and retrieval: A selective review. Microscopy Research \& Technique, 51, 6-28.

GARNER, W. R. (1974). The processing of information and structure. Potomac, MD: Erlbaum.

Giovanello, K. S., Schnyer, D. M., \& Verfaellie, M. (2004). A critical role for the anterior hippocampus in relational memory: Evidence from an fMRI study comparing associative and item recognition. Hippocampus, 14, 5-8.

Gooding, P. A., Mayes, A. R., \& Meudell, P. R. (1997). Indirect memory performance is not sensitive to a shift of local context. European Journal of Cognitive Psychology, 9, 289-312.

Gratton, G., Coles, M. G. H., \& Donchin, E. (1983). A new method for off-line removal of ocular artifact. Electroencephalography \& Clinical Neurophysiology, 55, 468-484.

Greenhouse, S. W., \& Geisser, S. (1959). On methods in the analysis of profile data. Psychometrika, 24, 95-112.

Groh-Bordin, C., Zimmer, H. D., \& EcKer, U. K. H. (2006). Has the butcher on the bus dyed his hair? When color changes modulate ERP correlates of familiarity and recollection. NeuroImage, 32, 1879-1890.

Groh-Bordin, C., Zimmer, H. D., \& Mecklinger, A. (2005). Feature binding in perceptual priming and in episodic object recognition: Evidence from event-related brain potentials. Cognitive Brain Research, 24, 556-567.

Guillem, F., Bicu, M., \& Debruille, J. B. (2001). Dissociating memory processes involved in direct and indirect tests with ERPs to unfamiliar faces. Cognitive Brain Research, 11, 113-125.

Holdstock, J. S. (2005). The role of the human medial temporal lobe in object recognition and object discrimination. Quarterly Journal of Experimental Psychology, 58B, 326-339.

Holdstock, J. S., Mayes, A. R., Roberts, N., Cezayirli, E., Isaac, C. L., O'Reilly, R. C., \& Norman, K. A. (2002). Under what conditions is recognition spared relative to recall after selective hippocampal damage in humans? Hippocampus, 12, 341-351.

Humphreys, M. S., Bain, J. D., \& Pike, R. (1989). Different ways to cue a coherent memory system: A theory for episodic, semantic, and procedural tasks. Psychological Review, 96, 208-233.

Johnson, M. K., \& Chalfonte, B. L. (1994). Binding complex memories: The role of reactivation and the hippocampus. In D. L. Schacter \& E. Tulving (Eds.), Memory systems 1994 (pp. 311-350). Cambridge, MA: MIT Press.

Joliceur, P. (1987). A size congruency effect in memory for visual shape. Memory \& Cognition, 15, 531-543.

MANDLER, G. (1980). Recognizing: The judgment of previous occurrence. Psychological Review, 87, 252-271.

Mayes, A. R., Holdstock, J. S., Isaac, C. L., Hunkin, N. M., \& RobERTS, N. (2002). Relative sparing of item recognition memory in a patient with adult-onset damage limited to the hippocampus. Hippocampus, 12, 325-340.

Mayes, A. R., Holdstock, J. S., IsaAc, C. L., Montaldi, D., Grigor, J., GuMmer, A., ET AL. (2004). Associative recognition in a patient with selective hippocampal lesions and relatively normal item recognition. Hippocampus, 14, 763-784. 
Mecklinger, A. (2000). Interfacing mind and brain: A neurocognitive model of recognition memory. Psychophysiology, 37, 565-582.

Murnane, K., Phelps, M. P., \& Malmberg, K. (1999). Contextdependent recognition memory: The ICE theory. Journal of Experimental Psychology: General, 128, 403-415.

Naveh-Benjamin, M. (2000). Adult age differences in memory performance: Tests of an associative deficit hypothesis. Journal of Experimental Psychology: Learning, Memory, \& Cognition, 26, 11701187.

Naveh-Benjamin, M. (2006). Binding of memories: Adult-age differences and the effects of divided attention in young adults on episodic memory. In H. D. Zimmer, A. Mecklinger, \& U. Lindenberger (Eds.), Handbook of binding and memory: Perspectives from cognitive neuroscience (pp. 627-656). Oxford: Oxford University Press.

O'Craven, K. M., Downing, P. E., \& Kanwisher, N. (1999). fMRI evidence for objects as the units of attentional selection. Nature, 401, 584-587.

PAller, K. A., \& Kutas, M. (1992). Brain potentials during memory retrieval provide neurophysiological support for the distinction between conscious recollection and priming. Journal of Cognitive Neuroscience, 4, 375-391.

Park, D. C., Puglisi, J. T., \& Lutz, R. (1982). Spatial memory in older adults: Effects of intentionality. Journal of Gerontology, 37, 330-335.

Park, D. C., Puglisi, J. T., \& Sovacool, M. (1983). Memory for pictures, words, and spatial location in older adults: Evidence for pictorial superiority. Journal of Gerontology, 38, 582-588.

Ranganath, C., \& Paller, K. A. (1999). Frontal brain potentials during recognition are modulated by requirements to retrieve perceptual detail. Neuron, 22, 605-613.

Reinitz, M. T. (2003). Feature binding in episodic memory: Roles of conscious awareness and intention. In T. Bajo \& J. Lupiáñez (Eds.), Abstracts of the13th Conference of the European Society of Cognitive Psychology in Granada, Spain, September 17-20 (pp. 123-124). Monachil: Imprenta Santa Rita.

Reinitz, M. T., \& Hannigan, S. L. (2001). Effects of simultaneous stimulus presentation and attention switching on memory conjunction errors. Journal of Memory \& Language, 44, 206-219.

Reinitz, M. T., \& Hannigan, S. L. (2004). False memories for compound words: Role of working memory. Memory \& Cognition, 32, 463-473.

Rugg, M. D., Walla, P., Schloerscheidt, A. M., Fletcher, P. C., Frith, C. D., \& Dolan, R. J. (1998). Neural correlates of depth of processing effects on recollection: Evidence from brain potentials and positron emission tomography. Experimental Brain Research, 123, 18-23.

SchloerscheidT, A. M., \& RugG, M. D. (2004). The impact of change in stimulus format on the electrophysiological indices of recognition. Neuropsychologia, 42, 451-466.

Senkfor, A. J., \& Van Petten, C. (1998). Who said what? An eventrelated potential investigation of source and item memory. Journal of Experimental Psychology: Learning, Memory, \& Cognition, 24, 1005-1025

Sмiтн, M. E. (1993). Neurophysiological manifestations of recollective experience during recognition memory judgments. Journal of Cognitive Neuroscience, 5, 1-13.

Smith, S. M., \& Vela, E. (2001). Environmental context-dependent memory: A review and meta-analysis. Psychonomic Bulletin \& Review, 8, 203-220.

SnOdgrass, J. G., \& Corwin, J. (1988). Pragmatics of measuring recognition memory: Applications to dementia and amnesia. Journal of Experimental Psychology: General, 117, 34-50.

Spencer, W. D., \& Raz, N. (1995). Differential effects of aging on memory for content and context: A meta-analysis. Psychology \& Aging, 10, 527-539.

SRINIVAS, K., \& Verfaellie, M. (2000). Orientation effects in amnesics' recognition memory: Familiarity-based access to object attributes. Journal of Memory \& Language, 43, 274-290.

Treisman, A. M. (1992). Perceiving and re-perceiving objects. American Psychologist, 47, 862-875.

Treisman, A. M. (2006). Object tokens, binding, and visual memory. In H. D. Zimmer, A. Mecklinger, \& U. Lindenberger (Eds.), Handbook of binding and memory: Perspectives from cognitive neuroscience (pp. 315-338). Oxford: Oxford University Press.

Troyer, A. K., \& Craik, F. I. M. (2000). The effect of divided attention on memory for items and their context. Canadian Journal of Experimental Psychology, 54, 161-170.

Tsivilis, D., Otten, L. J., \& RugG, M. D. (2001). Context effects on the neural correlates of recognition memory: An electrophysiological study. Neuron, 31, 497-505.

Van Petten, C., Luka, B. J., Rubin, S. R., \& Ryan, J. P. (2002). Frontal brain activity predicts individual performance in an associative memory exclusion task. Cerebral Cortex, 12, 1180-1192.

Van Petten, C., Senkfor, A. J., \& Newberg, W. M. (2000). Memory for drawings in locations: Spatial source memory and event-related potentials. Psychophysiology, 37, 551-564.

Voss, J. L., \& PAller, K. A. (2006). Fluent conceptual processing and explicit memory for faces are electrophysiologically distinct. Journal of Neuroscience, 26, 926-933.

WAlker, P., \& Cuthbert, L. (1998). Remembering visual feature conjunctions: Visual memory for shape-color associations is objectbased. Visual Cognition, 5, 409-455.

Wilding, E. L., Doyle, M. C., \& RugG, M. D. (1995). Recognition memory with and without retrieval of context: An event-related potential study. Neuropsychologia, 33, 743-767.

Wilding, E. L., Fraser, C. S., \& Herron, J. E. (2005). Indexing strategic retrieval of colour information with event-related potentials. $C o g$ nitive Brain Research, 25, 19-32.

WiLdING, E. L., \& RugG, M. D. (1996). An event-related potential study of recognition memory with and without retrieval of source. Brain, 119, 889-905.

Wilton, R. N. (1989). The structure of memory: Evidence concerning the recall of surface and background color of shapes. Quarterly Journal of Experimental Psychology: 41A, 579-598.

Yonelinas, A. P. (2002). The nature of recollection and familiarity: A review of 30 years of research. Journal of Memory \& Language, 46, 441-517.

Yonelinas, A. P., \& JACOBY, L. L. (1995). The relation between remembering and knowing as bases for recognition: Effects of size congruency. Journal of Memory \& Language, 34, 622-643.

Yovel, G., \& Paller, K. A. (2004). The neural basis of the butcher-onthe-bus phenomenon: When a face seems familiar but is not remembered. NeuroImage, 21, 789-800.

Zimmer, H. D. (1995). Size and orientation of objects in explicit and implicit memory: A reversal of the dissociation between perceptual similarity and type of test. Psychological Research, 57, 260-273.

Zimmer, H. D., Mecklinger, A., \& Lindenberger, U. (Eds.) (2006a). Handbook of binding and memory: Perspectives from cognitive neuroscience. Oxford: Oxford University Press.

Zimmer, H. D., Mecklinger, A., \& Lindenberger, U. (2006b). Levels of binding: Types, mechanisms, and functions of binding in remembering. In H. D. Zimmer, A. Mecklinger, \& U. Lindenberger (Eds.), Handbook of binding and memory: Perspectives from cognitive neuroscience (pp. 3-24). Oxford: Oxford University Press.

Zimmer, H. D., \& Steiner, A. (2003). Color specificity in episodic and in object recognition with enhanced color impact. European Journal of Experimental Psychology, 15, 349-370.

Zimmer, H. D., \& Steiner, A. (2007). Memory of colours as a function of the style of pictures and the deliberateness of colour encoding. Manuscript submitted for publication.

\section{NOTES}

1. Available online at www.shaker.de/Online-Gesamtkatalog/Details idc? ISBN = 3-8322-2871-3

2. Line drawings (i.e., only the contours of the drawing are colored, as opposed to the type of fully colored silhouettes used in the present experiments) could be an exception: Color could be perceived as a feature of the medium (e.g., the chalk). This might be the reason Friedman et al. (2005), manipulating the color of line drawings, did not report a significant congruency effect on the mid-frontal ERP old-new effect.

3 . On the basis of a prestudy (cf. Ecker et al., 2004) in which performances were a lot worse, we introduced dual study-test phases and presented every study item twice. Thus, the high performance level was strived for also because no effects on accuracy had been predicted.

4. In light of ceiling effects, hit and false alarm rates of 1 and 0 , respectively, were adjusted by subtracting or adding $1 /(2 N)$, in order to allow for the calculation of $\mathrm{Br}$. 
5. Note that figures depicting all the electrodes analyzed (instead of ROI data only) are available in an online supplement at www.psychonomic.org/ archive (see details at the end of the article).

6. It may be of interest to the ERP expert that this was confirmed by current source density analysis. This is presented in the online supplement as well (see details at the end of the article).

7. Note that although the significant ROIs are the same as those in the respective analysis of Time Window 1 , the effects in the two time windows still differ topographically, reflecting the more widespread and posterior distribution of the later effect: A $2 \times 3 \times 3$ ANOVA with the factors of time window (1 and 2), AP, and laterality, including only same difference waves of the color group, revealed a significant three-way interaction $[F(4,56)=4.96, p<.01, \varepsilon=.68]$.

8. Note that in the additional single-electrode analysis, the condition $X$ Lat and the condition $\times$ AP $\times$ Lat interactions were also significant.

9. See the online supplement (details at the end of the article) for CSD maps, again suggesting overlapping contributions of two distinct anterior and posterior cortical sources.

10. Our notion of activation of objects and their intrinsic features in whole may lead the reader to assume that color recognition should be close to perfect whenever an object itself is recognized as old. However, this is only an ideal way of thinking: For instance, color might not have been encoded in the first place, information might decay, or there might be access problems. After all, even the information in object tokens consists of different pieces of information bound together, and binding is always prone to failure. Of course, there will also be some old objects that are only guessed to be old, so the feature decision can only be a guess, too.

\section{ARCHIVED MATERIALS}

The following materials associated with this article may be accessed through the Psychonomic Society's Norms, Stimuli, and Data archive, www.psychonomic.org/archive.

To access this file, search the archive for this article using the journal name (Memory \& Cognition), the first author's name (Ecker), and the publication year (2007).

FILE: Ecker-MC-2007.zip

DESCRIPTION: The compressed archive file contains one file: EckerMC-Supplement.pdf, containing figures showing all electrodes analyzed and current source density analyses.

AUTHOR's E-MAIL ADDRESS: u.ecker@mx.uni-saarland.de.

Author's Web site: www.braincog.de.

(Manuscript received August 22, 2005; revision accepted for publication June 6,2006 .) 